\title{
Were early pterosaurs inept terrestrial locomotors?
}

Mark P Witton

Pterodactyloid pterosaurs are widely interpreted as terrestrially competent, erect-limbed quadrupeds, but the terrestrial capabilities of non-pterodactyloids are largely thought to have been poor. This is commonly justified by the absence of a non-pterodactyloid footprint record, suggestions that the expansive uropatagia common to early pterosaurs would restrict hindlimb motion in walking or running, and the presence of sprawling forelimbs in some species. Here, these arguments are re-visited and mostly found wanting. Restriction of limb mobility is not a problem faced by extant animals with extensive fight membranes, including species which routinely utilise terrestrial locomotion. The absence of non-pterodactyloid footprints is not necessarily tied to functional or biomechanical constraints. As with other fully terrestrial clades with poor ichnological records, biases in behaviour, preservation, sampling and interpretation likely contribute to the deficit of early pterosaur ichnites. Suggestions that non-pterodactyloids have slender, mechanically weak limbs are demonstrably countered by the proportionally long and robust limbs of many Triassic and Jurassic species. Novel assessments of pterosaur forelimb anatomies conflict with notions that all non-pterodactyloids were obligated to sprawling forelimb postures. Sprawling forelimbs seem appropriate for species with ventrally-restricted glenoid articulations (seemingly occurring in rhamphorhynchines and campylognathoidids). However, some early pterosaurs, such as Dimorphodon macronyx and wukongopterids, have glenoid arthrologies which are not ventrally restricted, and their distal humeral anatomy resembles those of pterodactyloids. It seems fully erect forelimb stances were possible in these pterosaurs, and may be probable given proposed links between pterodactyloid-like distal humeral morphology and forces incurred through erect forelimb postures. Further indications of terrestrial habits include antungual sesamoids, which occur in the manus and pes anatomy of many early pterosaur species, and only occur elsewhere in terrestrial reptiles, possibly developing through frequent interactions of large claws with firm substrates. It is argued that characteristics possibly associated with terrestriality are deeply nested within Pterosauria and not restricted to Pterodactyloidea as previously thought, and that pterodactyloid-like levels of terrestrial competency may have been possible in at least some early pterosaurs. 


\section{Were early pterosaurs inept terrestrial locomotors?}

3

4 Mark P. Witton

5 School of Earth and Environmental Sciences, University of Portsmouth, Burnaby Building,

6 Burnaby Road, Portsmouth, PO1 3QL, UK

7 Correspondence address.mark.witton@port.ac.uk
9

\section{Abstract}

Pterodactyloid pterosaurs are widely interpreted as terrestrially competent, erect-limbed quadrupeds, but the terrestrial capabilities of non-pterodactyloids are largely thought to have been poor. This is commonly justified by the absence of a non-pterodactyloid footprint record, suggestions that the expansive uropatagia common to early pterosaurs would restrict hindlimb motion in walking or running, and the presence of sprawling forelimbs in some species. Here, these arguments are re-visited and mostly found wanting. Restriction of limb mobility is not a problem faced by extant animals with extensive fight membranes, including species which routinely utilise terrestrial locomotion. The absence of non-pterodactyloid footprints is not necessarily tied to functional or biomechanical constraints. As with other fully terrestrial clades with poor ichnological records, biases in behaviour, preservation, sampling and interpretation likely contribute to the deficit of early pterosaur ichnites. Suggestions that non-pterodactyloids have slender, mechanically weak limbs are demonstrably countered by the proportionally long and robust limbs of many Triassic and Jurassic species. Novel assessments of pterosaur forelimb anatomies conflict with notions that all non-pterodactyloids were obligated to sprawling forelimb postures. Sprawling forelimbs seem appropriate for species with ventrally-restricted glenoid articulations (seemingly occurring in rhamphorhynchines and campylognathoidids). However, some early pterosaurs, such as Dimorphodon macronyx and wukongopterids, have glenoid arthrologies which are not ventrally restricted, and their distal humeral anatomy resembles those of pterodactyloids. It seems fully erect forelimb stances were possible in these pterosaurs, and may be probable given proposed links between pterodactyloid-like humeral morphology and forces incurred through erect forelimb postures. Further indications of terrestrial habits include antungual sesamoids, which occur in the manus and pes anatomy of many early pterosaur species, and only occur elsewhere in terrestrial reptiles, possibly developing through frequent 


\section{Introduction}

interactions of large claws with firm substrates. It is argued that characteristics possibly associated with terrestriality are deeply nested within Pterosauria and not restricted to Pterodactyloidea as previously thought, and that pterodactyloid-like levels of terrestrial competency may have been possible in at least some early pterosaurs.

The terrestrial competency of pterosaurs was keenly debated during the 1980s and 1990s, when the utility of bipedal and quadrupedal gaits, orientation and posture of the extremities, as well as overall terrestriality were discussed at length (Fig. 1, Padian 1983a, b; Padian and Olsen 1984; Wellnhofer 1988; Unwin 1988, 1989, 1996a, 1999; Lockley et al. 1995; Bennett 1997a; Clark et al. 1998; see Witton 2013 for a recent overview). The current consensus emerged when Pteraichnus trackways, first identified by Stokes (1957) as pterosaurian, but argued to be of crocodylomorph origin by Padian and Olsen (1984) and Unwin (1989), were convincingly demonstrated as belonging to pterodactyloid pterosaurs (Lockley et al. 1995; Bennett 1997a; Unwin 1996a, 1999; also see Kubo 2008). This reappraisal started the construction of a compelling case for pterodactyloids as terrestrially competent quadrupeds with plantigrade feet and parasagittal gaits, a hypothesis now strengthened by numerous trackway discoveries (e.g. Mazin et al. 1995, 2003; Lockley and Wright 2003; Hwang et al. 2002; Padian 2003; Lockley et al. 2008) but also functional analyses of pterosaur anatomy (e.g. Bennett 1997a; Clark et al. 1998; Sangster 2003; Wilkinson 2008; Witton and Naish 2008; Fujiwara and Hutchinson 2012; Costa et al. 2013; Hyder et al. 2014).

Although it seems that the basic tenets of pterodactyloid terrestrial locomotion are understood, the same cannot be said for non-pterodactyloids. Research into the terrestrial capacity of early pterosaurs is entirely based on interpretations of their functional anatomy because their trackways remain elusive (Unwin 2005; Lockley et al. 2008; Whyte and Romano 2014). Such considerations are relatively few in number and have reached varying conclusions, either arguing for non-pterodactyloids as terrestrially competent, digitigrade bird-like bipeds which could not easily reach the substrate with their forelimbs (Fig. 1a; Padian 1983a, b, 1985, 2003, 2008); as widely-sprawled quadrupeds, limited to rotatory gaits (as defined by Padian et al. 2010) and ill- 
64 suited to movement on the ground, but possibly adept at climbing (Unwin 1987, 1988, 1989, 65 1999; 2005; Unwin and Bakhurina 1994); or as quadrupeds with erect hindlimbs, capable of arboreal locomotion and powerful leaping (Bennett 1997b) or bipedal running (Padian 2008a, b,

67 c)

68

To some extent, discussions of non-pterodactyloid terrestriality have been intertwined with debates over pterosaur bipedality, as many of the foundations of this hypothesis were set using non-pterodactyloids (Padian 1983a, b). Pterosaur bipedality has always been controversial (Bennett 1997a, p. 107) and has inspired numerous analyses. Most have suggested that habitual bipedalism - either bird-like or otherwise - is unlikely for any pterosaur. Criticisms of this concept include all pterosaurs having a centre of gravity situated towards the shoulders (Wellnhofer 1988; Bennett 1997a; Sangster 2003; Wilkinson 2008); a pedal morphology illsuited to digitigrady (Bennett 1997a; Clark et al. 1998); lever arms of proximal hindlimb musculature which perform poorly at postures imposed by bipedality (Fastnacht 2005; Costa et al. 2013); an inability to neatly fold the forelimbs (Wilkinson 2008), and forelimb strength scaling regimes contrasting with those of flying bipeds, but matching those of quadrupeds (Habib 2008). The inability of pterosaur forelimbs to reach the ground has also been disputed (Unwin 1996a; Bennett 1997a), although Padian (1983b, 2003a, b) maintains that the limb proportions of some species, in concert with perceived limited limb motion at the shoulder, dictates facultative bipedality for some pterosaurs. Functional evidence casting doubt on bipedal postures in pterosaurs is consistent with a wealth of trackway data showing pterosaurs as quadrupedal animals with plantigrade feet (e.g. Mazin et al. 1995, 2003; Lockley and Wright 2003; Hwang et al. 2002; Padian 2003; Lockley et al. 2008), and is further bolstered by the unique fit of pterosaur anatomy to these tracks (Lockley et al. 1995; Bennett 1997a; Unwin 1996a). Note that further experimentation with extant crocodilian trackmakers has cast further doubt on perceived similarities between Pteraichnus tracks and those of crocodylomorphs (Kubo 2008; contra. Padian and Oslen 1984; Padian 2003).

92 Of the several interpretations of non-pterodactyloid terrestrial locomotion outlined above, the 93 proposal that they were relatively ineffective terrestrial quadrupeds has gained the largest 94 acceptance (e.g. Unwin 1987, 1988, 1989, 1999; 2005; Unwin and Bakhurina 1994; Ősi 2010; 
Butler et al. 2013; Benson et al. 2014; Whyte and Romano 2014). The assumed contrast in terrestrial abilities between non-pterodactyloids and pterodactyloids has influenced considerations of not only non-pterodactyloid palaeobiology (e.g. lifestyle and diets - see Unwin 2005; Ösi 2010) but also the evolution of Pterosauria as a whole. Some recent workers have considered the origin of pterodactyloids a 'terrestrialisation' of pterosaurs (Unwin 2005; Butler et al. 2013), and a radical evolutionary departure from the primarily scansorial and volant habits used by earlier members of the group.

The concept of grounded non-pterodactyloids as poor terrestrial locomotors relies on three oftrepeated hypotheses. The first concerns the expansive uropatagium which extended between the hindlimbs of non-pterodactyloids, supported distally by long fifth pedal digits (Fig. 2; Sharov 1971; Unwin and Bakhurina 1994; Wild 1994; Kellner et al. 2009). This is reasoned to have restricted independent hindlimb motion and stride length, limited speed and agility, and hindered movement through complex, vegetated environments (e.g. Unwin 1988, 1999; 2005; Ösi 2011). The reduction of fifth toe length in pterodactyloids is interpreted as signifying the loss or reduction of this membrane, as evidenced by a pterodactyloid specimen with reduced hindlimb membranes lacking medial contact (Wellnhofer 1987). This 'decoupling' of the hindlimbs from one another is thought to have permitted longer strides and more effective, faster terrestrial locomotion in pterodactyloids, explaining their relative success in inland settings over their ancestors (e.g. Unwin 1988, 1999, 2005; Ősi 2011).

The absence of pterosaur trackways from Triassic to Middle Jurassic rocks is a second piece of evidence cited for non-pterodactyloid terrestrial incompetency. The pterosaur body fossil record begins in at least the Norian but, to date, no definitively identified pterosaur trackways occur in rocks pre-dating the Aalenian (Lockley et al. 2008; Whyte and Romano 2014). The oldest occurrence of pterosaur tracks roughly coincides with the oldest evidence of pterodactyloids (Andres et al. 2014; Whyte and Romano 2014) and is seen as evidence for pterosaurs becoming 'terrestrialised', it being assumed that pterodactyloid anatomical nuances allowed exploitation of settings such as tidal flats and lake margins, and creation of a track record (Unwin 2005; Butler et al. 2012). Non-pterodactyloids, by contrast, are assumed so poorly adapted for walking and 
125 running that they scarcely used such forms of locomotion, and thus rarely left footprints (Unwin 126 2005).

128 Both of these concepts are in keeping with a third hypothesis, that non-pterodactyloids had 129 sprawling forelimbs, and perhaps hindlimbs as well (Wellnhofer 1975; Unwin 1988, 1999, 2005;

130 Padian 2008b). It has been argued that these would limit quadrupedal walking speeds and force

131 reliance on other forms of locomotion - bipedal running or flight - to move rapidly (Unwin 132 1988, 1999, 2005; Padian 2008b). Although some have argued that the hindlimbs of early 133 pterosaurs were erect and powerfully muscled (e.g. Padian 1983a, b, 2008b; Bennett 1997b;

134 Elgin et al. 2011), these observations have not influenced some considerations of non135 pterodactyloid terrestrial locomotion (Unwin 1988, 2005). However, even among those 136 proposing erect hindlimbs, the terrestrial prospects of non-pterodactyloids are not considered

137 highly. Padian (2008a, b) has suggested that a combination of erect hindlimbs and sprawled 138 forelimbs would incline early pterosaur torsos anteriorly, and, in concert with limited forelimb 139 reach, render them ill-suited to terrestrial locomotion - at least as quadrupeds (this is considered 140 one line of evidence for bipedal habits). In recent years, views that early pterosaurs were inept

141 terrestrial animals have been presented as established and important parts of the pterosaur 142 evolutionary history, and said to explain patterns within the pterosaur fossil record (Unwin 1999, 143 2005; Butler et al. 2012; Benson et al. 2014).

145 These assumptions have become established despite the low number of dedicated assessments 146 into non-pterodactyloid locomotion. There have been considerably fewer studies into non147 pterodactyloid functionality than there are for pterodactyloids, and particularly so in recent years. 148 This probably reflects the larger amount of material available for studies into pterodactyloid 149 mechanics: along with footprints and tracks, many pterodactyloids are known from three150 dimensional material which lends itself better to functional studies than the mostly flattened and 151 fragmentary remains forming the non-pterodactyloid record. Nevertheless, some non152 pterodactyloid anatomies are well enough known to permit evaluation of arguments suggesting 153 poor terrestriality in these early forms. This is attempted here, with the three principle hypotheses 154 underlying most assessments of non-pterodactyloid terrestriality being considered: 
1. Did the large uropatagium of non-pterodactyloids restrict hindlimb function during terrestrial locomotion?

2. Is the absence of non-pterodactyloids trackways related to their terrestrial capabilities?

Institutional abbreviations

162 BSP, Bayerische Staatssammlung für Paläontologie und Geologie, Berlin, Germany; HGM, 163 Henan Geological Museum, Zhengzhou, China; GPIT, Geologisch-Paläontologisches Institut und Museum, Universität Tübingen, Germany; GSM, Geological Survey Museum, Keyworth; UK; IVPP, Institute of Vertebrate Palaeontology and Palaeoanthropology, Beijing, China; JPM, Jehol Paleontological Museum, Chengde, China; MCSNB, Museum Civico di Scienze Naturali di Bergamo, Italy; MFSN. Museo Friulano di Storia Naturale, Udine, Italy; MJML, Museum of Jurassic Marine Life, Kimmeridge, UK; MPUM, Museo Paleontologia Universitá di Milano, Italy; NHMUK, Natural History Museum, London, UK; PIN, Paleontological Institute, Moscow, Russia; SMNS, Staatliches Museum für Naturkunde Stuttgart, Germany.

\section{Materials and Methods}

\section{Systematic declaration}

174 Pterosaur systematics, and particularly those of early taxa, are currently highly controversial.

With so little agreement on multiple aspects of early pterosaur phylogeny including clade content, group definitions, and appropriate nomenclature (e.g. Unwin 2003; Kellner 2003; Wang et al. 2009; Kellner 2010; Dalla Vecchia 2009; Lü et al. 2010, 2012; Witton 2013; Andres and Meyers 2013; Andres et al. 2014), accurate discussion of pterosaur systematics requires regular citation of the specific taxonomy being followed (e.g. Andres and Meyers 2013) or frequent mentions of conflicting phylogenies (e.g. Witton 2013). Neither approach is practical or makes

181 for compelling reading. Thus, unless otherwise stated, this paper uses the nomenclature and 182 taxonomy of the non-pterodactyloid phylogeny of Lü et al. (2012). Dalla Vecchia (2009), Wang 183 et al. (2010) and Andres and Meyers (2013) offer alternative contemporary schemes.

\section{Material}


186 A number of specimens inform the discussion provided here, but key material includes three-

187 dimensionally preserved remains of Dimorphodon macronyx, a well-known Sinemurian, Liassic

188 non-pterodactyloid from Dorset, UK. Observations were chiefly made on the holotype NHMUK

189 R1034, a partial skeleton, and the near complete skeleton NHMUK 41412-13. Both specimens,

190 although partially embedded in matrix, are largely three dimensionally preserved and sufficiently

191 prepared to appreciate most aspects of limb girdle and limb anatomy, especially when viewed in

192 concert with other, less complete Dimorphodon material in the Natural History Museum,

193 London. Additional study was made on a near-complete three-dimensional rhamphorhynchine

194 scapulocoracoid from the Callovian-Oxfordian Oxford Clay, UK, NHMUK R5672. Wellnhofer

195 (1975) referred this specimen to Rhamphorhynchus sp., but diagnostic characters for this genus

196 are presently only known in the skull anatomy and limb proportions of this genus (Bennett

197 1995). While undoubtedly Rhamphorhynchus-like, NHMUK R5672 is conservatively considered

198 an indeterminate rhamphorhynchine here, echoing taxonomic suggestions by Unwin (1996b).

200 Results

201

202

203

204

205

206

207

208

209

210

211

212

213

214 Many gliding and flying mammals possess large, hindlimb-spanning uropatagia comparable in

215 size to those of non-pterodactyloids (Fig. 2). A number of these species are terrestrially

216

\section{Did the large uropatagium of non-pterodactyloids restrict hindlimb function during} terrestrial locomotion?

The inference that relatively large uropatagia impeded early pterosaur terrestrial habits has received no detailed evaluation, despite its confident presentation in some literature ("There can be no doubt that this shackling of the limbs must have hindered pterosaurs as they sought to move around on the ground" - Unwin 2005, p. 204). It might be presumed that attributes of fossil pterosaur soft-tissues or observations on modern animals with similar membrane structures support this assertion, but it is only the relatively large size of early pterosaur uropatagia which is cited in favour of this idea (e.g. Unwin and Bakhurina 1994; Unwin 2005). While it is difficult to evaluate the effects of soft-tissues on non-pterodactyloid hindlimb kinematics in the absence of footprints, evidence from pterosaur body fossils, and the anatomy and behaviour of modern animals, conflict with proposals that expansive uropatagia impeded early pterosaur terrestriality. proficient (e.g. Sollberger 1940; Nowark 1994; Stafford et al. 2003; Riskin et al. 2006; Meijaard 
217 et al. 2006), some spending considerable amounts of time on the ground in pursuit of food or

218 refuge using fast, complex and sometimes strenuous behaviours (Sollberger 1940; Daniel 1976;

219 Nowark 1994; Pyare and Longland 2002; Riskin et al. 2006). These animals are not confined to

220 barren habitats, predator-free environments or the result of reduced competition from other

221 terrestrial creatures. Rather, they inhabit complex, predator-filled habitats and have persisted for

222 many millions of years in some regions (Hand et al. 2009). Examples include the New Zealand

223 lesser short-tailed bat, Mystacina tuberculata, which is reported as having "rodent-like agility on

224 the ground and on trunks, branches, and kiekie vines" by Daniel (1976; p. 397). Common

225 vampires, Desmodus rotundus, rely on their terrestrial skills to stealthily stalk hosts or quickly

226 evade danger using forelimb-propelled galloping (Nowark 1994; Riskin and Hermanson 2005;

227 Riskin et al. 2006). Flying squirrels, such as Glaucomys species, forage on the ground, are

228 capable of running, and have membranes resilient to frequent digging for fungal food sources

229 (Sollberger 1940). Similarly, membranes of Mystacina bats withstand crevice-crawling as well

230 as digging (Daniel 1979). Clearly, the grounded activities of these animals are not impeded by

231 their patagia, nor do their membranes snag on obstacles or become easily damaged. Presumably,

232 membrane elasticity plays a role in reducing impedance to terrestrial activity, both allowing the

233 limbs to move freely as well as drawing the membranes close to the body to prevent interference

234 with the environment or limb motion. The extent of such membrane shrinkage can be extreme,

235 rendering them almost indiscernible in some circumstances (Meijaard et al. 2006). Critically,

236 while some membrane-bound extant animals are poor terrestrial locomotors, this has not been

237 linked to membrane size or distribution, but instead to aspects of skeletal morphology, limb

238 strength or myology (Riskin et al. 2005).

239

240 Certain bats and flying squirrels show that large uropatagia do not rule out terrestrial potential in

241 volant mammals, but are they suitable models for pterosaurs? Fossils of pterosaur wing

242 membranes show some similarities to those of modern volant mammals in that they were likely

243 elastic in their proximal regions. Pterosaur brachiopatagia are stiffened by structural fibres

244 distally, but other membrane components - including the uropatagium - lack rigid structural

245 fibres and are widely considered to have been compliant (e.g. Padian and Rayner 1993; Unwin

246 and Bakhurina 1994; Bennett 2000; Frey et al. 2003). Unwin and Bakhurina (1994), describing

247 the uropatagium of Sordes pilosus, comment specifically on this, stating “....adjacent to the body 
248 the [structural] fibres are shorter, more sinuous and loosely packed, indicating that the

249 propatagium, uropatagium and proximal regions of the cheiropatagium were somewhat softer

250 and more elastic" (p. 64). From this, it can be expected that all pterosaur membranes would

251 contract significantly when the limbs were not extended to flight position, as occurs in many

252 volant mammals, clearing them of obstacles and permitting stretching of the membranes during

253 walking or running. Some evidence for this contraction may be seen in pterosaur fossils with

254 preserved membranes (Elgin et al. 2011). Trackways made by running pterodactyloids indirectly

255 demonstrate how elastic their proximal membranes must have been, allowing track makers to

256 take strides of considerable magnitude (Mazin et al. 2003) despite membranes stretching from

257 the distal hindlimb to their hands (Elgin et al. 2011). The expansion and contraction of

258 brachiopatagia in running pterodactyloids was probably no greater than that experienced by non-

259 pterodactyloid uropatagia during terrestrial activity.

260

261 Even if the hindlimb strides of non-pterodactyloids were restricted by membranes, pterosaurs

262 were likely capable of circumventing this issue by using asymmetrical, bounding gaits (Witton

263 and Habib 2010; Witton 2013; Hyder et al. 2014). Indeed, both the fore- and hindlimbs of

264 pterosaurs have been noted for their strength and leaping potential (Padian 1983a, Bennett

265 1997b; Habib 2008; Witton and Habib 2010), and there are obvious parallels between forelimb-

266 dominated Desmodus galloping and recent, compelling hypotheses concerning forelimb use in

267 pterosaur launch (Habib 2008). Pterosaurian bounding locomotion may be countered by

268 exclusive trackway evidence for symmetrical gaits in pterodactyloids (e.g. Stokes 1957; Mazin et

269 al. 1995, 2003; Lockley and Wright 2003; Hwang et al. 2002), but it remains unclear if these

270 gaits were employed by all pterosaurs, all the time, nor is it clear if interpretations of these tracks

271 are applicable to non-pterodactyloids. Bounding gaits are at least tenable from a functional and

272 biomechanical perspective.

273

274 In light of these observations, the proposal that early pterosaurs were terrestrially hindered by

275 their membranes is peculiar. It relies on the uncertain assumption that the uropatagium was

276 especially restrictive compared to other pterosaur wing membranes and behavioural restrictions -

277 membranes snagging on obstacles and limiting stride length - which have no precedent among

278 modern pterosaur analogues. Clear evidence demonstrating broad uropatagia were barriers to 
279 early pterosaur terrestriality has yet to be presented, whereas what we know of pterosaur soft280 tissues and modern animals with similar anatomy indicates that their membranes likely had little, 281 if any, impact on terrestrial potential.

2. Is the absence of non-pterodactyloids trackways related to terrestrial capabilities?

284 The view that a lack of early pterosaur trackways must equate to their terrestrial ineptitude (e.g. 285 Unwin 2005; Butler et al. 2013) relies on a very literal interpretation of the pterosaur fossil 286 record and an assumption that we can distinguish genuine absences of fossil phenomena from 287 biases affecting fossil datasets. There are reasons to consider both these assertions uncertain. 288

The non-pterodactyloid body fossil record is not only poorer than that of pterodactyloids, but 290 also many contemporary terrestrial tetrapod groups (e.g. Benton and Spencer 1995; Kielan291 Jaworowska et al. 2004). It is particularly impoverished in terrestrial basins (Butler et al. 2013). 292 This is thought to reflect the general lack of inland or near-shore pterosaur-bearing Lagerstätten 293 before the Late Jurassic; the small body sizes and low preservation potential of early pterosaurs; 294 a possibly restricted distribution of the group in its early history; or perhaps existence of the first pterosaurs in habitats unconducive to fossilisation and sediment accumulation - inland forests or upland environments (Bennett 1997b; Unwin 2005; Witton 2013; Butler et al. 2013). Regardless of the cause, recent studies have concluded that recorded patterns of Triassic and Jurassic pterosaur diversity - the interval dominated by non-pterodactyloids - have little statistical significance (e.g. Butler et al. 2013; Upchurch et al. 2014), and that our understanding of early pterosaur history remains generally poor. This is difficult to reconcile with suggestions that the lack of an early pterosaur fossils - specifically their track record - is somehow significant. If understanding of the early pterosaur record is demonstrably limited, how can any apparent trends or patterns in that data be confidently interpreted, and especially those reliant on an absence of 304 data? It seems unwise to link the absence of a track record to a very specific cause, such as functional anatomy (and especially so given the lack of detailed research into early pterosaur terrestriality) when there are a number of reasons why non-pterodactyloids may not have an ichnological record. If non-pterodactyloids were genuinely rare in terrestrial basins - as their record currently 
310 indicates - their likelihood of creating traces must also be low. Likewise, it seems most early

311 pterosaurs were small, with wingspans of 1-2 m (O'Sullivan et al. 2013) and corresponding

312 masses of 0.55-3.26 kg (using data from Witton 2008). Their footprints would thus be small and

313 shallow, without substantial underprinting, and require exceptional conditions for impression,

314 fossilisation and discovery. In contrast, pterodactyloids are generally larger bodied than early

315 pterosaurs (Hone and Benton 2007; Benson et al. 2014), which may constitute creation of

316 deeper, longer-lasting tracks which are better suited to fossilisation and detection. A related

317 problem concerns our ability to distinguish the footprints of pterodactyloids from those expected

318 of non-pterodactyloids (Lockley et al. 2008): all pterosaurs have the same basic manus and pes

319 structure, the only exception being the longer fifth toe in non-pterodactyloids. Given the role of

320 this structure in supporting the uropatagium, it may have been held aloft when walking (Lockley

321 et al. 2008). If so, the tracks of all pterosaurs might look similar, and some alleged Jurassic

322 pterodactyloid ichnites may be misidentified.

323

324 It should also not be assumed that early pterosaurs and pterodactyloids occupied ecologies with

325 similar track-making potential. The start of the pterosaur footprint record in the Middle Jurassic

326 roughly corresponds with the emergence of pterodactyloid clades predicted to be waders,

327 suspension-feeders and molluscivores (ctenochasmatoid and dsungaripterids - Unwin 2005;

328 Witton 2013). Such animals are expected to routinely patrol lake margins and other habitats

329 suitable to footprint preservation in search of food. Lockley et al. $(2003,2008)$ note that

330 pterodactyloid tracks are frequently associated with invertebrate traces and occasional feeding

331 marks, which may indicate foraging was a common factor in pterosaur ichnite creation, inferring

332 ecological influences on the delayed start of the pterosaur ichnological record. By contrast, non-

333 pterodactyloids are largely perceived as pelagic piscivores or insectivores (Wellnhofer 1975;

334 Wild 1978; Chatterjee and Templin 2004; Ösi 2010; Witton 2008, 2013), neither of which are

335 habits lending themselves to sustained terrestrial activity on mudflats, water margins or other

336 settings liable to preserving footprints.

337

338 Perhaps most importantly, early pterosaurs are not alone in having a very sparse track record.

339 The tracks and traces of many fully terrestrial Mesozoic clades are surprisingly poorly known -

340 examples include geographically widespread, long-lived lineages with good body fossil records, 
341 such as Mesozoic Mammaliaformes, tyrannosaurids and ceratopsids (Lockley and Hunt 1995;

342 Kielan-Jaworowska et al. 2004; McCrea et al. 2014). Not only are the ichnological records of

343 these groups poor - restricted to single localities in some cases - but many ichnites referred to

344 them are controversially identified (Kielan-Jaworowska et al. 2004; McCrea et al. 2014). This

345 occurs despite these animals seemingly being abundant (as evidenced by their good body fossil

346 records) and fully terrestrial in their habits, thus potentially creating tracks in virtually all of their

347 activities (unlike pterosaurs, which, in being volant, avoided track creation much of the time). In

348 contrast to perceptions of the pterosaur track record however, the sparse trackways of Mesozoic

349 Mammaliaformes or certain dinosaur clades are not interpreted as signs terrestrial ineptitude, but

350 as biases of behaviour, ecology, preservation, sampling or interpretation.

352 Ultimately, while the absence of early pterosaur footprints is an intriguing phenomenon of the

353 pterosaur record, and one with possible implications for the development of terrestriality in

354 Pterosauria, its significance cannot be divorced from a number of factors unrelated to functional

355 morphology. As with any case supported by negative evidence, data deficits can only be

356 interpreted so far, especially when related datasets are demonstrably poor. Considering the

357 absence of early pterosaur tracks as significant requires ignorance of not only statistics on the

358 quality of the pterosaur fossil record, but also data concerning early pterosaur palaeobiology and

359 the broader ichnological record. Other sources of evidence should be pursued for more reliable

360 insights into the development of pterosaur terrestriality.

361

362

363

364

365 pterodactyloids from assessments of their limb joint arthrology (e.g. Wellnhofer 1975; Unwin 1988, 1999; 2005; Padian 2008b). These suggestions have mostly applied to the forelimbs, but some have suggested that both limbsets were constrained to sprawling stances (Unwin 1988, 1999, 2005). Unwin (1988) argued that the Dimorphodon femoral-pelvic joint projected the femur anterolaterally and somewhat dorsally when 'naturally articulated', while the tibiotarsus was capable of twisting medially at the knee, permitting the foot to face forwards. This is said to allow for semi-erect or sprawling stances, which are in accordance with suggested similarities between the pelves of Dimorphodon and the sprawling or semi-erect archosauriform Euparkeria 
372 capensis (Unwin 1988). Computer modelling has also predicted entirely sprawling stances and

373 rotatory gaits for non-pterodactyloids through a digital model of Rhamphorhynchus (Fig. 1B;

374 Unwin 2005). The methodology behind this has not been presented, but the resultant digital non-

375 pterodactyloid model 'Roborhamphus' shows hindlimbs projecting entirely laterally from the

376 body, similarly-sprawling forelimbs, low clearance from the ground and slow walking speeds

377 (Unwin 2005). The latter is seemingly a consequence of the limited reach afforded by the

378 sprawling limbs.

379

380 There are several reasons to think that the non-pterodactyloid hindlimb did not sprawl. Firstly,

381 the assumption that a 'natural articulation' of the hindlimb can be determined from acetabulum

382 and femoral head morphology (Unwin 1988) is problematic. As evidenced by debates over

383 'osteological neutral pose' in fossil animal necks (e.g. Stevens and Parrish 1999, Taylor et al.

384 2009; Taylor and Wedel 2013; Stevens 2013), attempts to determine 'neutral' or 'natural' poses

385 of animal joints rely on arbitrary assignments of optimal joint configurations which often have

386 little or no significance to typical animal postures (Taylor et al. 2009). It is probably unwise to

387 suggest the hindlimb of Dimorphodon sprawled based on acetabulum and femoral head

388 morphology alone.

389

390 Secondly, the pelves of Dimorphodon and other early pterosaurs are clearly distinguished from

391 those of Euparkeria and other sprawling animals in having a well-developed preacetabular

392 process (Unwin 1988; Hyder et al. 2014). In this respect, non-pterodactyloid pelves resemble

393 those of other ornithodirans - including pterodactyloids - and mammals. These taxa are

394 characterised by erect limbs, the preacetabular process anchoring large hip flexors for moving

395 the hindlimb forward in the parasagittal plane (Hyder et al. 2014), and assessments of pterosaur

396 hindlimb muscle mechanics seem to confirm that the pterosaur pelvic and femoral

397 musculoskeletal system is optimally configured for an erect stance (Fastnacht 2006; Costa et al.

398 2013). Furthermore, while arguments for bipedal, pronograde pterosaurs with parasagittal

399 hindlimbs and digitigrade pedes (Padian 1983a, 1985) have been largely criticised in recent years

400 (e.g. Wellnhofer 1988; Bennett 1997a; Clark et al. 1998; Fastnacht 2005 - also see above),

401 observations that their hip, knee and ankle articulations have hallmarks of upright limb 
402 functionality have been borne out by further study (Bennett 1997b; Padian 2008a, b; Fastnacht 403 2005; Costa et al. 2013).

404

405 Thirdly, virtually all recent models of pterosaur evolution suggest taxa with erect hindlimbs 406 bracket non-pterodactyloids, with Scleromochlus taylori and non-pterosaurian ornithodirans on 407 one side, and pterodactyloids the other (Sereno 1991; Benton 1999, Hone and Benton 2008; 408 Nesbitt 2011; but also see Bennett 2013). This implicates erect hindlimb postures as probably 409 ancestral for Pterosauria and, given the similarity of their pelvic and hindlimb osteology to their 410 nearest probable relatives, there is little reason to assume non-pterodactyloids deviated from this 411 ancestral state (Bennett 1996b; Padian 2008a; Hyder et al. 2014). It seems that multiple lines of 412 evidence indicate erect hindlimbs across Pterosauria, including all known non-pterodactyloids.

414 Relatively little has been said on the stature of non-pterodactyloid forelimbs, however.

415 Traditionally, they have been reconstructed as sprawling. Wellnhofer (1975) observed that the 416 glenoid of Rhamphorhynchus muensteri projected laterally and permitted anterodorsal and 417 posteroventral motion of the humerus, but that anterior and posterior motion was limited, and 418 that the humerus could not be adducted below the level of the scapula. Padian (1983a) suggested 419 that the glenoid of Dimorphodon permitted a $90^{\circ}$ arc of rotation, most of it dorsal to the glenoid, 420 also suggested the shoulder joint of Dorygnathus permitted little movement below the frontal 421 plane (Fig. 1C; Padian 2008b). This is said to limit Dorygnathus to a sprawling forelimb stance 422 during quadrupedal locomotion which could not match pace with the erect hindlimbs during 423 running, for which bipedality was employed (Padian 2008b). This configuration, which Padian 424 (2003, 2008a) considers typical of all 'basal pterosaurs' (presumably non-pterodactyloids), is 425 also thought to limit ventral reach of the forelimb to the extent that bipedal locomotion must be 426 used, as the pectoral region is depressed significantly below that of the hindlimb in a state 427 considered awkward for effective locomotion (Padian 1983b, 2003, 2008a, b). Unwin (2005) 428 showed the digital 'Roborhamphus' forelimbs in a sprawling fashion somewhat consistent with 429 these models (Fig. 1B). 430

431 Notions that non-pterodactyloid forelimbs were confined to sprawling stances by their glenoids 432 are based in part on the pectoral girdles of rhamphorhynchine pterosaurs (e.g. Wellnhofer 1975; 
433 Padian 2008b). The glenoids of these animals are typified by the isolated, but well-preserved 434 scapulocoracoid of an Oxford Clay rhamphorhynchine, NHMUK R5672 (Fig. 3D-G, I). Here, 435 the glenoid is a laterally prominent structure with a long axis aligned with the base of the 436 scapula. The anterior and posterior ends are bordered by a prominent lower tubercle and 437 supraglenoidal buttress, respectively, between which occurs a deeply-curved, saddle-shaped 438 articular surface. This wraps almost $90^{\circ}$ from the lateral face to the dorsal, suggesting ample 439 humeral motion lateral and dorsal to the glenoid. The articular face is anteroposteriorly broadest 440 in its dorsal region and most constrained laterally. The ventral extent of the glenoid is marked by 441 a laterally-projecting ridge between the posterior buttress and anterior tubercle. This ridge is 442 continuous with the lower extent of the scapula, supraglenoidal buttress and lower tubercle so 443 that the ventral face of the glenoid is a wide, flat surface instead of a saddle shaped-joint like that 444 of the dorsal region. As noted by previous authors (e.g. Wellnhofer 1975; Padian 2008a, b), such 445 glenoids clearly did not permit humeral adduction below the level of the scapula, and likely 446 limited fore- and aft-motion of the humerus at maximal adduction. Humeral motion was likely 447 less constrained dorsally, however. Given their marked dorsoventral asymmetry, these glenoids 448 are hereafter referred to as 'asymmetric'.

450 A survey of non-pterodactyloid remains suggests asymmetric glenoids occur in a number of taxa, 451 including the Jurassic rhamphorhynchines Rhamphorhynchus muensteri (see numerous examples 452 in Wellnhofer 1975); the recently-named Kimmeridge Clay Rhamphorhynchus etchesi (MJML453 K1597, O'Sullivan and Martill, 2015); Dorygnathus banthensis (GPIT 1645/1, Padian 2008b); 454 and Sericipterus wucaiwanensis (IVPP V14725, Andres et al. 2010). They thus appear to be 455 typical for rhamphorhynchines, and further occurrences may occur within Campylognathoididae, 456 including the Triassic Eudimorphodon ranzii (MCSNB 2888, Wild 1978), and Jurassic 457 Campylognathoides liasicus (SMNS 11879, Padian 2008c). Asymmetric glenoids may be more 458 widely spread across non-pterodactyloids than this, but establishing their frequency is 459 complicated by a deficit of good preservation and frequently unmet requirements for particular 460 scapulocoracoid orientations in flattened specimens. Accordingly, the shape of the glenoid

461 cannot be established for many taxa which may otherwise be considered well-known, such as the 462 Anurognathidae. 
464 Asymmetric glenoids are not the only shoulder morph of non-pterodactyloids, however: the well465 preserved glenoids on Dimorphodon macronyx specimens NHMUK R1034 and 41412-13 are 466 rather differently constructed (Fig. 3A-C, H). Although following the same basic configuration 467 as other non-pterodactyloids, these specimens have a larger supraglenoidal buttress which 468 projects further ventrally than the lower tubercle. The dorsal portion of the glenoid articular face 469 is similar to that described above, but the ventral portion wraps onto the underside of the glenoid 470 until it meets the scapula shaft, instead of terminating at an elevated scapular margin. This gives 471 the glenoid a spool- or hourglass-like appearance in lateral view, and presents no obvious 472 restriction to adducting the humerus to a subvertical position. As with the rest of the glenoid, the 473 ventral articular region is widely open anteroposteriorly (although not as much as the dorsal 474 region) and is estimated to permit $90^{\circ}$ of anteroposterior humeral rotation beneath the body. This 475 observation contrasts with previous assessments of Dimorphodon glenoid morphology, which 476 suggested anatomy and arthrological range akin to the 'asymmetric' morph outlined above 477 (Padian 1983b, 2003, 2008b). As demonstrated in Fig. 3H-I, the ventral morphologies and likely 478 arthrological ranges of these glenoids are quite distinct.

480 Glenoids like those seen in Dimorphodon are hereafter referred to as 'symmetric', after their 481 relatively similar dorsal and ventral articular surfaces. It seems such glenoids were rare in non482 pterodactyloids: other than Dimorphodon, only the wukongopterids Darwinopterus 483 linglongtaensis (IVPP V16049, Wang et al. 2010) and Darwinopterus robustodens (HGM 484 41HIIII-0309A; Lü et al. 2011) seem to possess them, although the caveats mentioned above 485 mean this assessment should not be considered definitive. It is notable that some aspects of 486 pterodactyloid glenoids are similar to this 'symmetric' condition, including the relatively large 487 supraglenoidal buttress, expansive articular face, and absence of an arthrologically prohibitive 488 ventral margin.

The two non-pterodactyloid glenoid morphologies identified here have different implications for 491 adoption of sprawling or erect postures. Asymmetric glenoids seem to obligate forelimb 492 sprawling, whereas symmetric glenoids could permit either sprawling or upright limb usage. As 493 noted above, relying on a single joint for insight into animal postures can be misleading, and 494 using only glenoid shape to infer forelimb postures in non-pterodactyloids may be unwise. 
495 Additional insights on the stances of these animals are afforded by aspects of their distal humeri, 496 however. The morphology of distal humeri seems characteristic of stance in extant quadrupeds, 497 and has been used to predict sprawling or erect limb carriage in extinct animals (Fujiwara and 498 Hutchinson 2012). This is possible because the size of osteological correlates of wrist flexor and 499 extensor muscles, as well as those of elbow extensors, provide insights into primary mechanical 500 loads placed on the distal humerus and, therefore, an insight into habitual forelimb postures

501 (Fujiwara and Hutchinson 2012). This method, grounded and tested in a biometric dataset of 318 502 living taxa, has obvious utility for fossil species where interpreting limb posture based on 503 arthrology alone can be controversial. Fujiwara and Hutchinson (2012) have already applied

504 their technique to a pterodactyloid (Anhanguera piscator) humerus and found it met expectations 505 of animals using an upright posture, agreeing with other predictions made from limb bone 506 arthrology and trackway data for erect forelimb use in pterodactyloids (e.g. Unwin 1996a;

507 Bennett 1997a; Mazin et al. 2003). Fujiwara and Hutchinson (2012) note that their conclusions

508 likely apply to other pterodactyloids, implying that morphological similarity to Anhanguera 509 distal humeri (which are broadly similar to those of other pterodactyloids, even accounting for

510 body size, Fig. 4 G-F) in any pterosaurs might suggest similar forelimb use and stance.

512 A survey of non-pterodactyloid humeri shows variation in their distal ends that correlate with 513 distinctions in their glenoid shape (Fig. 4). The distal humeri of pterosaurs with asymmetric 514 glenoids possess markedly reduced medial and lateral epicondyles so that, in anterior view, their 515 distal humeri show relatively little expansion from the diaphyseal shafts. For this reason, the 516 palmar aspect of their distal humeri are dominated by the capitula and trochlea (Fig. 4 D-F). This 517 is seen in at least Rhamphorhynchus (Wellnhofer 1975) and Dorygnathus (SMNS 51827, SMNS 518 50164, see Padian 2008b), and perhaps also Eudimorphodon (MCSNB 2888) and

519 Campylognathoides (see examples in Padian 2008c), although the flattened, often oblique

520 preservation of humeri in specimens of the latter species prohibits full confidence in this 521 observation (Wild 1978; Padian 2008c). The lack of well-developed lateral and medial 522 epicondyles in these humeri contrasts with the pterodactyloid condition, in which these structures 523 are prominent and the distal humeri are expanded (Fig. 4 G-F). However, the distal humeri of 524 Dimorphodon (NHMUK 42016, YPM 350) and the probable wukongopterid 525 Archaeoistiodactylus linglongtaensis (JPM04-0008, see Sullivan et al. 2013 for comments on the 
526 phylogenetic position of this species) are much more pterodactyloid-like. In these humeri, well-

527 developed lateral and medial epicondyles create a splayed distal termination much broader than 528 either the humeral diaphysis or the combined width of the capitulum and trochlea (Fig. 4 A-C,

529 Padian 1983a; Lü and Fucha 2010). In Dimorphodon at least, the medial condyle is also distally

530 displaced compared to the lateral. This results in the distal ends of Dimorphodon and

531 wukongopterid humeri being clearly different to those of rhamphorhynchines and

532 campylognathoidids, but morphologically very similar to those of pterodactyloids (Fig. 4 G-I).

533

534 The correlation between these humeral conditions and glenoid morphology is potentially

535 significant. The similarity of Dimorphodon and wukongopterid humeri to those of

536 pterodactyloids implies a similar mechanical regime being experienced at the elbow region

537 which, following Fujiwara and Hutchinson (2012) and other studies on pterodactyloid humeral

538 orientation when walking (e.g. Unwin 1996a; Bennett 1997a; Mazin et al. 2003), might indicate

539 the employment of upright stances. As noted above, portions of the symmetric glenoid articular

540 surface project ventrally in a manner expected for animals with erect forelimbs. The large, open

541 junction between the ventral articular surface, lower extent of the supraglenoidal buttress and the

542 lateral face of the scapula seems capable - perhaps even well-suited - to bolstering a fully

543 adducted forelimb for standing and walking. These anatomies raise the possibility of

544 wukongopterids and Dimorphodon being capable of erect forelimb postures. If, as noted by

545 Fujiwara and Hutchinson (2012), pterodactyloid-like distal humeri correlate with an upright

546 forelimb stance, such postures may even be likely. In any case, the assumption that sprawling

547 forelimbs were common to all non-pterodactyloids clearly warrants further investigation.

548 Moreover, the possibility that some early pterosaurs could fully adduct their humeri suggests that

549 reaching the ground in a quadrupedal stance may not have been difficult, as has been proposed

550 (Padian 1983b; 2008a, b).

551

552 The humeral morphology in rhamphorhynchine and campylognathoidid non-pterodactyloids

553 differs from those seen in erect-limbed pterodactyloids (Fujiwara and Hutchinson 2012) and also

554 suits their glenoid morphology. Asymmetric glenoids seem to prohibit humeral adduction into an

555 erect stance, and it would be predicted that correlates for a different set of forelimb muscles -

556 likely those suited to sprawling - would be emphasised at the distal humerus compared to those 
557 seen in pterodactyloids. Lack of indications of erect poses suggests these pterosaurs fit

558 'traditional' models of sprawling forelimbs in non-pterodactyloids (e.g. Wellnhofer 1975; Unwin

559

560

561

562

563

564

565

566

567

568

569

570

571

572

573

574

575

576

577

578

579

580

581

582

583

584

585

586

587

2005; Padian 2008b). It might be predicted that their stance and walking gaits required relatively little wrist motion, as evidenced by their weakly developed epicondyles for muscle attachment related to carpal operation.

\section{Discussion}

Other indications of terrestrial competency in non-pterodactyloids

The possibility that some non-pterodactyloids were capable of fully upright stances, and unconstrained during terrestrial locomotion by their membranes, might have broad implications for our perception of their palaeobiology and role in pterosaur evolutionary history. Note, however, that these are not the only aspects of early pterosaur anatomy indicating greater terrestrial potential than previously anticipated.

It has been suggested that non-pterodactyloid limbs are too short and slender for effective terrestrial locomotion (Fig. 5, Ösi 2011). This is probably an over-generalisation: early pterosaur anatomy is quite disparate in many respects (Witton 2013). Several well-known taxa do possess short and/or slender limbs (e.g. Fig. 5E-F), but Triassic and Jurassic taxa such as Dimorphodon, anurognathids and Preondactylus bufarinii possess long, robust, and near-equally sized limbs with well-developed extremities (Fig. 5A-D; Owen 1870; Dalla Vecchia 1998; Bennett 2007; Padian 2008a). Indeed, the limbs of some non-pterodactyloids are more substantially developed and proportionate than those of seemingly terrestrially-competent pterodactyloids, such as azhdarchids (Witton and Naish 2008). It has been noted that several early pterosaur hindlimb skeletons possess features of subcursoriality (Padian 1983b; 2003, 2008a, b), and this is also true of their forelimbs. Subcursorial features include long limbs relative to their bodies, joints with hinge-like mobility, short and massive propodia, slender and distally reduced/fused fibulae, digitigrade manus and elongate metapodia (see Coombs 1978, p. 399 and 402). It bears repeating that the limbs of pterosaurs - including those of non-pterodactyloids - have been frequently identified as powerfully muscled and strongly built for leaping and flying (Padian 1983a, b, 2003; 2008a, b; Bennett 1997b; Fastnacht 2005; Habib 2008; Witton and Habib 2010), and were therefore likely capable of supporting some grounded activity, perhaps even sustained and 
588

589

590

591

592

593

594

595

596

597

598

599

600

601

602

603

604

605

606

607

608

609

610

611

612

613

614

615

616

617

618

energetic terrestrial behaviours. It is likely that the slender, disproportionate limbs of some better known non-pterodactyloids such as Rhamphorhynchus have biased opinions on the terrestrial ability non-pterodactyloids as a whole: considered independently, the long, proportionate and robust limbs of genera such as Dimorphodon, anurognathids and Preondactylus might be considered well-suited to terrestrial locomotion.

The digits of several non-pterodactyloid species are also adorned with features which may betray routine terrestrial habits: antungual sesamoids (Fig. 6). These small, round bones are situated on the dorsal surfaces of the penultimate manual phalanges of many Triassic and Lower Jurassic pterosaur specimens, including the Triassic taxa Eudimorphodon ranzii (MCSNB 2888), Carniadactylus rosenfeldi (MFSN 1797), Peteinosaurus zambellii (MCSNB 2887), the "Eudimorphodon" specimen MCSNB 8950, the "Peteinosaurus" specimen MCSNB 3359 (Wild 1978, 1994; Dalla Vecchia 2009) as well as the Jurassic pterosaurs Dorygnathus (e.g. Fig. 6C, BSP 1938 I 49; see also Padian 2008b) and Dimorphodon (Fig. 6A, NHMUK 41212; NHMUK R1034; see Padian 1983a, Unwin 1988). Dimorphodon is unusual in also bearing pedal antungual sesamoids, spreading their distribution across all clawed digits (Fig. 6B, GSM 1546; Unwin 1988). Antungual sesamoids are present in an osteologically immature specimen of Eudimorphodon (MPUM 6009; Wild 1978), suggesting they are not just confined to gerontic, well-ossified adults.

Pterosaur antungual sesamoids are consistently preserved dorsally adjacent to the articular condyles of penultimate phalanges and were presumably situated within the tendons of the digit extensors (Bennett 2008). Their function has not been explored in detail, but two studies (Unwin 1988 and Bennett 1997b) cite them as part of a suite of characters important to pterosaur grasping and climbing capabilities. Anatomies related to grasping and climbing are relatively well explored (see Sustaita et al. 2013 for a recent review) but, to this author's knowledge, extension of the ungual is not generally associated with this behaviour. An exception might be climbing geckos, which retract adhesive pads situated on the distal ends of their digits before each step (Zaaf et al. 1999; Russel and Higham 2009). However, these geckos famously adhere themselves to substrates via manipulation of molecular forces, not with claws, and their climbing methods are unlikely to mirror those used by pterosaurs. 
620 Antungual sesamoids are currently only known from three tetrapod groups: pterosaurs, and 621 terrestrial reptiles: several squamate lineages (Haines 1969; Jerez et al. 2009; Otero and Hoyos 622 2013) and the semiaquatic 'bottom walking' Triassic turtle Proganochelys (Gaffney 1990). 623 Gaffney (1990) proposed that antungual sesamoids confer functions typical of other reptile 624 sesamoids: increasing tendon moment arm lengths around joints, ensuring nutrient delivery to 625 tendons by limiting strain or pressure on joints articulated to their extremes (Haines 1969), or 626 strengthening tendons (Nussbaum 1982). High mechanical stresses on the dorsal side of

627 phalangeal-ungual joints seem to be the most likely catalyst for antungual sesamoid 628 development. Perhaps the only shared functional attributes between pterosaurs, squamates and 629 Proganochelys are large unguals and the potential to walk on firm substrates. It may be that these 630 two factors alone can account for antungual sesamoid development. One possibility is that 631 deflection of large, curving unguals by hard surfaces induce pressure on the extensor tendon, 632 promoting the development of a sesamoid to maintain tendon nutrient flow during sustained 633 bouts of standing and walking (Fig. 6Dii). Alternatively, deliberate hyperextension of claws may 634 promote antungual sesamoid development as means to increase the extensor tendon moment 635 arm, and thus improve efficiency of claw retraction (Fig. 6Diii). It is notable that pterosaurs with 636 antungual sesamoids possess expanded, deeply grooved penultimate phalangeal terminations and 637 large ungual extensor tubercles (Fig. 6A-C), similar to the phalanges of animals with 638 hyperextensible digits, such as cats, dromaeosaurids and schizotherine chalicotheres (Coombs 639 1983; Gonyea and Ashworth 1975; Parsons and Parsons 2009). By contrast, pterosaurs lacking 640 antungual sesamoids have relatively small, weakly developed phalangeal-ungual joints (e.g. 641 Wellnhofer 1975; Clark et al. 1998), suggesting limited potential for hyperextension. Ungual 642 hyperextension has evolved repeatedly within terrestrial tetrapods to avoid claw blunting (e.g. 643 Gonyea and Ashworth 1975; Coombs 1983) or to release strong grips, as demonstrated by many 644 modern geckos which, when walking, retract the ends of their digits before each step (Zaaf et al. 645 1999; Russel and Higham 2009): the possibility it occurred in pterosaurs is not unreasonable.

646 Indeed, claw retraction has been proposed as an explanation for the lack of ungual traces in some 647 pterodactyloid ichnites (Frey et al. 2003). 
649 These hypotheses share frequent ungual interaction with hard substrates as the chief adaptive 650 pressure for antungual sesamoid development. Sustained activity in terrestrial settings is perhaps

651 the most likely cause of this interaction, and congruent with the seemingly-exclusive

652 development of antungual sesamoids in terrestrialised taxa such as squamates and

653 Proganochelys. If antungual sesamoids do represent such adaptations, their development in non654 pterodactyloids may represent further evidence of terrestrial habits in early pterosaurs.

655

656 The terrestrial proficiency of early pterosaurs

657 The considerations of early pterosaur limb and limb girdle functions offered here suggest views 658 of non-pterodactyloid palaeobiology may warrant more detailed consideration. Existing models 659 of pterosaur locomotory mechanics, where pterodactyloids are adaptable, 'terrestrialised' 660 pterosaurs and their forebears were confined to climbing and flying, are perhaps over-simplistic.

661 Not only are common arguments for terrestrially-inept early pterosaurs problematic, but 662 anatomies consistent with fully erect stances and other possible hallmarks of competent 663 terrestriality seem to be deeply nested within Pterosauria. These findings are the latest in a series 664 showing that pterosaur palaeobiology is much richer, more diverse and complex than previously 665 anticipated (see Witton 2013 for an overview).

666

667 Assessing the evolutionary pathways of the anatomies described here is complicated by the lack 668 of consensus over non-pterodactyloid phylogeny (Unwin 2003; Kellner 2003; Wang et al. 2009; 669 Kellner 2010; Dalla Vecchia 2009; Lü et al. 2010, 2012; Witton 2013; Andres and Meyers 2013; 670 Andres et al. 2014). Some tentative conclusions may be drawn, however. The distribution of 671 glenoid and humeral morphologies identified above is complicated, with no set of features 672 limited to specific clades or 'grades' of pterosaurs (Fig. 7). Potential signatures of erect postures 673 appear early in pterosaur evolution: Dimorphodon indicates that symmetric glenoids and 674 pterodactyloid-like humeral features had developed by the Sinemurian at the latest, and 675 pterosaurs with elongate, robust limbs (e.g. Peteinosaurus, "Eudimorphodon" specimen MCSNB 6763359 , Preondactylus) represent some of the oldest known pterosaurs (Carnian/Norian). Given 677 that likely pterosaur outgroups such as dinosauromorphs and Scleromochlus bore strong, erect 678 limbs (e.g. Sereno 1991; Benton 1999), it is possible that these early pterosaurs retained 679 characteristics of efficient terrestriality from immediate pterosaur ancestors. This might be in 
680 keeping with models of pterosaurs evolving from terrestrially- or scansorially-adapted ancestors 681 in inland environments (Padian 1985, 2008a; Bennett 1997b; Witton 2013; Andres et al. 2014), 682 before spreading to marine habitats (Andres et al. 2014). Taxa likely utilising sprawling 683 forelimbs tend to occur further from the pterosaur root however, suggesting this 'traditional' 684 stance might be a derived feature of clades such as Rhamphorhynchinae and 685 Campylognathoididae, and perhaps associated with the development of increasingly pelagic 686 lifestyles (see below).

687

688 How the development of these features relates to possible evidence for fully erect limbs in the 689 pterodactyloid sister group, Wukongopteridae, is intriguing. Their Callovian/Oxfordian (Lü et al. 690 2010) appearance in the fossil record approximates the appearance of pterosaur footprints as well 691 as the first pterodactyloids (Andres et al. 2014), making questions about distinguishing 692 pterodactyloid tracks from those of non-pterodactyloids all the more pertinent (Lockley et al. 693 2008). Were wukongopterids involved in an upper Jurassic 'terrestrial radiation' of pterosaurs, 694 and was this part of a separate 'terrestrialisation event' to that potentially indicated by earlier, 695 Dimorphodon-like pterosaurs? Do wukongopterids represent a lineage of pterosaurs which 696 retained plesiomorphic glenoid and humeral morphologies from much earlier pterosaurs, or were 697 these reversed from sprawling ancestors? Future discoveries of Jurassic and Triassic pterosaurs 698 in terrestrial basins and further resolution on the phylogeny of early pterosaurs may shed light on 699 these questions.

701 Concerning the specifics of terrestrial locomotion in different non-pterodactyloid taxa: the view 702 of early pterosaurs as forelimb-sprawling terrestrial locomotors (e.g. Wellnhofer 1975; Padian 703 2008b) seems appropriate for at least rhamphorhynchines and campylognathoidids (Fig. 8A), 704 although how limiting their sprawled or crouched forelimbs were to walking and running 705 remains to be determined. Padian's (1983b, 2008a, b) suggestion that the torsos of quadrupedal 706 pterosaurs with sprawling forelimbs would be anteriorly inclined, and thus ill-suited to terrestrial 707 locomotion, is questionable. As demonstrated by the alternative reconstructions of such 708 pterosaurs provided in Fig. 5, torso inclination seems reliant on assumptions made when 709 restoring pterosaur skeletons - such as enhancement of hindlimb height through elevated 710 (digitigrade) ankles (compare Fig. 5E-F with Padian's 2008b Dorygnathus illustration in Fig. 
711 1C). In any case, the fact that numerous fossil and extant quadrupedal animals have anteriorly-

712 sloping backs and variable limb girdle heights when standing and walking (examples include

713 protorosaurs, modern and fossil crocodylomorphs, several dinosaur clades (diplodocoids,

714 stegosaurids, ceratopsids), and many small mammals lagomorphs, rodents, certain bats)

715 questions what significance this observation has on terrestriality. Other views that sprawling

716 gaits are inherently 'primitive' or inferior to erect ones, or somehow limit movement speed

717 (Unwin 2005) are problematic, as demonstrated by the tremendous success of sprawling

718 tetrapods both today and in Deep Time (Russell and Bels 2001). Although perhaps ill-suited to

719 sustained terrestrial locomotion, sprawling can be an effective, perhaps superior locomotory

720 kinematic for rapid acceleration, sprinting and climbing (Russell and Bels 2001). Indeed,

721 specialist lifestyles promote the retention or development of sprawling limbs in many species

722 (McElroy et al. 2008). Thus, the sprawling forelimbs of rhamphorhynchines and

723 campylognathoidids are not necessarily means to assume low terrestrial competency, and

724 arguments that sprawling pterosaurs would be limited to slow, ponderous locomotion do not

725 reflect the sometimes explosive and powerful abilities of modern sprawling amphibians, reptiles

726 and mammals (contra. Unwin 2005, Padian 2008b). Note that the limbs of galloping vampire

727 bats are sprawled (Riskin et al. 2006), a fact worth considering when arguing that

728 rhamphorhynchines and campylognathoidids required bipedal stances for rapid terrestrial

729 movement (e.g. Padian 2008b, c).

730

731 Nevertheless, because sustained terrestrial locomotion seems better served by erect limbs, the

732 indication that rhamphorhychines and campylognathoidids had sprawling forelimbs might be

733 consistent with predictions that these pterosaurs were relatively flight-reliant, seabird-like

734 species (see functional and palaeoecological evidence discussed by Wellnhofer 1975; Wild 1978;

735 Chatterjee and Templin 2004; Witton 2008, 2013, etc.). Like some seabirds, these pterosaurs

736 may have relied on flight for long-distance movement rather than terrestrial locomotion, and

737 their anatomy may reflect adaptive biases towards the former (e.g. Kaiser 2007; Abourachid and

738 Höfling 2012). For instance, parallels may be drawn between the restricted shoulder arthrology

739 of asymmetric glenoids and the energy-saving arthrological 'locks' found in the shoulders of

740 modern soaring birds (e.g. Meyers and Stakebake 2005). If antungual sesamoids are, as proposed

741 here, indicators of routine claw interaction with the ground, their presence in Dorygnathus, 
742 Carniadactylus and Eudimorphodon still suggest frequent terrestrial activities however. It may

743 be that these pterosaurs routinely landed to forage or roost but performed only limited walking or

744 running activities when grounded, while other habits - perhaps hanging or climbing -

745 necessitated large, trenchant claws and associated sesamoids. The sprawling stance of their

746 forelimbs is well suited to climbing behaviour (Russell and Nels 2001), as are the particularly

747 large and robust third manual digits of Dorygnathus (Fig. 6C; Padian 2008b)

748

749 With symmetrical glenoids and pterodactyloid-like distal humeri, it is possible Dimorphodon and 750 wukongopterids could utilise fully upright gaits and had pterodactyloid-like terrestrial

751 capabilities. Dimorphodon particularly embodies many 'subcursorial' features (long, robust

752 limbs; stout propodia, reduced fibulae, etc.) and it may have been capable of not only sustained,

753 but also relatively fast terrestrial activity (Fig. 8B). Especially well-developed appendages and

754 possession of antungual sesamoids on all clawed digits might signify that Dimorphodon was not

755 unduly reliant on flight, as do data suggesting it was particularly heavy for its wingspan and a

756 relatively ineffective, perhaps short-distance flier (Brower and Veinus 1980; Witton 2008, 2013,

757 in prep.; Henderson 2010). Scansorial features of the Dimorphodon skeleton (e.g. elongate

758 penultimate phalanges, asymmetrical pes structure, claw curvature - see Unwin 1988, Clark et

759 al. 1998; Witton 2013) marry with conclusions drawn here to present it as a terrestrial generalist,

760 capable of running, walking and climbing as well as flight. Many extant terrestrial animals with

761 mobile limb joints and long limbs - such as rodents, bovids, carnivorans, etc. - are as adept at

762 climbing as they are walking and running, to the extent that some measures of their

763 ecomorphospace overlap significantly with scansorial animals (e.g. Samuels et al. 2013): the

764 identification of climbing adaptations in some early pterosaurs does preclude terrestrial

765 proficiency. The suggested diet of insects and small vertebrates for Dimorphodon, based on its

766 skull morphology, tooth shape and dental wear patterns (Ösi 2010), is concordant with generally

767 terrestrial habits (Fig. 8B). Wukongopterid pterosaurs may have also been capable terrestrial

768 locomotors, although their limbs are not as powerfully built as those of Dimorphodon and some

769 aspects of their flight anatomy, such as their pteroids, are more substantially developed (Witton

770 2013). Like many small modern birds, wukongopterids may have been proficient enough to

771 move through terrestrial settings without flight - perhaps in search of insect prey (Lü et al. 2011;

772 Witton 2013) - but seem more aerially capable and flight-ready than the heavyset Dimorphodon. 
774 Concluding remarks

775 The assessment of non-pterodactyloid terrestrial locomotion offered here demonstrates that our

776

777

778

779

780

781

782

783

784

785

\section{6 \\ Acknowledgements}

787

788

789

790

791

792

793

794

\section{5}

796

797

798

799

800

801

802 pterosaur specimens.

\section{References}

understanding of functionality and locomotory mechanics in early pterosaurs is limited to the extent that basic differences in limb skeleton construction have yet to be noted in detail. It is hoped this work will inspire further investigation into the functionality of these animals. As here, such studies will likely be hampered by the quality of non-pterodactyloid fossils, where even complete specimens can be too extensively crushed or poorly preserved to show the anatomies needed for functional interpretation. However, there is clearly greater potential for understanding early pterosaur functionality than currently realised and, until this has been researched more thoroughly, caution is urged against making generalisations about the terrestrial competency of non-pterodactyloids, and its role in the evolution of Pterosauria.

Lorna Steel and Sandra Chapman are thanked for repeated access to specimens in their care and for assistance obtaining literature. Michael Habib, Luis Chiappe and an anonymous referee are thanked for providing comments on this work, as are Hans Thewissen, Peter Binfield and Matt Wedel for their editorial contributions. David Martill, Liz Martin and Michael O'Sullivan are thanked for discussions of early pterosaur functionality. David Hone, Ross Elgin, David Unwin and Calum Davies are thanked for sharing excellent photographs of German and Chinese

Andres, B., Clark, J. M., and Xing, X. (2010). A new rhamphorhynchid pterosaur from the Upper Jurassic of Xinjiang, China, and the phylogenetic relationships of basal pterosaurs. Journal of Vertebrate Paleontology, 30, 163-187.

Andres, B., and Myers, T. S. (2012). Lone star pterosaurs. Earth and Environmental Science Transactions of the Royal Society of Edinburgh, 103, 383-398.

Andres, B., Clark, J., and Xu, X. (2014). The earliest pterodactyloid and the origin of the group. Current Biology, 24, 1011-1016. 
803 Abourachid, A. and Höfling, E. (2012). The legs: a key to bird evolutionary success. Journal of 804 Ornithology, 153, 193-198.

805 Bennett, S. C. (1995). A statistical study of Rhamphorhynchus from the Solnhofen Limestone of 806 Germany, year-classes of a single large species. Journal of Paleontology, 69, 569-580.

807 Bennett, S. C. (1997a). Terrestrial locomotion of pterosaurs: a reconstruction based on 808 Pteraichnus trackways. Journal of Vertebrate Paleontology, 17, 104-113.

809 Bennett, S. C. (1997b). The arboreal leaping theory of the origin of pterosaur flight. Historical 810 Biology, 12, 265-290.

811 Bennett, S. C. (2000). Pterosaur flight: the role of actinofibrils in wing function. Historical 812 Biology, 14, 255-284.

813 Bennett, S. C. (2003). Morphological evolution of the pectoral girdle of pterosaurs: myology and 814 function. In: Buffetaut, E., and Mazin, J-M. (eds) Evolution and Palaeobiology of Pterosaurs. 815 Geological Society of London Geological Society, London, Special Publications, 217, 191816215.

817 Bennett, S. C. (2007). A second specimen of the pterosaur Anurognathus ammoni.

818 Paläontologische Zeitschrift, 81, 376-398.

819 Bennett, S. C. (2008). Morphological evolution of the wing of pterosaurs: myology and 820 function. Zitteliana, B28, 127-141.

821 Bennett, S. C. (2013). The phylogenetic position of the Pterosauria within the Archosauromorpha 822 re-examined. Historical Biology, 25, 545-563.

823 Benson, R. B., Frigot, R. A., Goswami, A., Andres, B., and Butler, R. J. (2014). Competition and 824 constraint drove Cope's rule in the evolution of giant flying reptiles. Nature Communications, $825 \quad 5,3567$.

826 Benton, M. J. (1999). Scleromochlus taylori and the origin of dinosaurs and 827 pterosaurs. Philosophical Transactions of the Royal Society of London. Series B: Biological 828 Sciences, 354, 1423-1446.

829 Benton, M. J., and Spencer, P. S. (1995). Fossil Reptiles of Great Britain. Chapman and Hall. 830 Brower, J. C. and Veinus, J. (1981). Allometry in pterosaurs. The University of Kansas $831 \quad$ Paleontological Contributions, 105, 1-32. 
832 Butler, R. J., Benson, R. B., and Barrett, P. M. (2013). Pterosaur diversity: untangling the

833 influence of sampling biases, Lagerstätten, and genuine biodiversity

834 signals. Palaeogeography, Palaeoclimatology, Palaeoecology, 372, 78-87.

835 Chatterjee, S., and Templin, R. J. (2004). Posture, locomotion, and paleoecology of pterosaurs.

836 Geological Society of America Special Publications, 376, 1-64.

837 Clark, J. M., and Hopson, J. A. (1998). Foot posture in a primitive pterosaur. Nature, 391, 886-

838889.

839 Coombs Jr, W. P. (1978). Theoretical aspects of cursorial adaptations in dinosaurs. Quarterly

840 Review of Biology, 53, 393-418.

841 Coombs, M. C. (1983). Large mammalian clawed herbivores: a comparative study. Transactions

842 of the American Philosophical Society, 73, 1-96.

843 Costa, F. R., Rocha-Barbosa, O., and Kellner, A. W. A. (2013). A biomechanical approach on

844 the optimal stance of Anhanguera piscator (Pterodactyloidea) and its implications for

845 pterosaur gait on land. Historical Biology, (ahead-of-print), 1-9.

846 Dalla Vecchia, F. M. (1998). New observations on the osteology and taxonomic status of

847 Preondactylus buffarinii Wild, 1984 (Reptilia, Pterosauria). Boll. Soc. Paleont. It, 36, 1997.

848 Dalla Vecchia, F. M. (2009). Anatomy and systematics of the pterosaur Carniadactylus gen. n.

849 rosenfeldi (Dalla Vecchia, 1995). Rivista Italiana di Paleontologia e stratigrafia, 115, 159-

850188.

851 Daniel, M. J. (1976). Feeding by the short-tailed bat (Mystacina tuberculata) on fruit and 852 possibly nectar. New Zealand journal of zoology, 3, 391-398.

853 Daniel, M. J. (1979). The New Zealand short-tailed bat, Mystacina tuberculata; a review of

854 present knowledge. New Zealand journal of zoology, 6(2), 357-370.

855 Elgin, R. A., Hone, D. W., and Frey, E. (2011). The extent of the pterosaur flight

856 membrane. Acta Palaeontologica Polonica, 56, 99-111.

857 Fastnacht, M. (2005). The first dsungaripterid pterosaur from the Kimmeridgian of Germany and 858 the biomechanics of pterosaur long bones. Acta Palaeontologica Polonica, 50, 273.

859 Frey, E., Tischlinger, H., Buchy, M. C., and Martill, D. M. (2003). New specimens of

860 Pterosauria (Reptilia) with soft parts with implications for pterosaurian anatomy and

861 locomotion. In: Buffetaut, E., and Mazin, J-M. (eds) Evolution and Palaeobiology of

862 Pterosaurs. Geological Society, London, Special Publications, 217, 233-266. 
863 Fujiwara, S. I., and Hutchinson, J. R. (2012). Elbow joint adductor moment arm as an indicator 864 of forelimb posture in extinct quadrupedal tetrapods. Proceedings of the Royal Society B:

865 Biological Sciences, 279, 2561-2570.

866 Gaffney, E. S. (1990). The comparative osteology of the Triassic turtle Proganochelys. Bulletin 867 of the American Museum of Natural History, 194. 1-263.

868 Gonyea, W., and Ashworth, R. (1975). The form and function of retractile claws in the Felidae 869 and other representative carnivorans. Journal of morphology, 145, 229-238.

870 Habib, M. B. (2008). Comparative evidence for quadrupedal launch in pterosaurs. Zitteliana, 871 B28, 159-166.

872 Haines, R. W. (1969). Epiphyses and sesamoids. Biology of the Reptilia, 1(part 3), 81-115.

873 Hand, S. J., Weisbecker, V., Beck, R. M., Archer, M., Godthelp, H., Tennyson, A. J., and 874 Worthy, T. H. (2009). Bats that walk: a new evolutionary hypothesis for the terrestrial 875 behaviour of New Zealand's endemic mystacinids. BMC Evolutionary Biology, 9, 169.

876 Henderson, D. M. (2010). Pterosaur body mass estimates from three-dimensional mathematical 877 slicing. Journal of Vertebrate Paleontology, 30, 768-785.

878 Hildebrand, M. (1994) Analysis of Vertebrate Structure, 4th ed. New York, NY: J. Wiley.

879 Hone, D. W. E., and Benton, M. J. (2007). Cope's Rule in the Pterosauria, and differing 880 perceptions of Cope's Rule at different taxonomic levels. Journal of Evolutionary Biology, 20, $881 \quad 1164-1170$.

882 Hone, D. W., and Benton, M. J. (2008). Contrasting supertree and total-evidence methods: the 883 origin of the pterosaurs. Zitteliana, B28, 35-60.

884 Hwang, K. G., Huh, M., Lockley, M. G., Unwin, D. M., and Wright, J. L. (2002). New pterosaur 885 tracks (Pteraichnidae) from the Late Cretaceous Uhangri Formation, southwestern

886 Korea. Geological Magazine, 139, 421-435.

887 Hyder, E. S., Witton, M. P., and Martill, D. M. (2014). Evolution of the pterosaur pelvis. Acta 888 Palaeontologica Polonica, 59, 109-124.

889 Jerez, A., Mangione, S., and Abdala, V. (2010). Occurrence and distribution of sesamoid bones 890 in squamates: a comparative approach. Acta Zoologica, 91, 295-305.

891 Kaiser, G. W. (2007). The Inner Bird: Anatomy and Evolution. UBC Press. 
892 Kellner, A. W. (2003). Pterosaur phylogeny and comments on the evolutionary history of the 893 group. In: Buffetaut, E., and Mazin, J-M. (eds) Evolution and Palaeobiology of Pterosaurs. 894 Geological Society, London, Special Publications, 217, 105-137.

895 Kellner, A. W. (2010). Comments on the Pteranodontidae (Pterosauria, Pterodactyloidea) with 896 the description of two new species. Anais da Academia Brasileira de Ciências, 82, 10638971084.

898 Kellner, A. W., Wang, X., Tischlinger, H., de Almeida Campos, D., Hone, D. W., and Meng, X. 899 (2010). The soft tissue of Jeholopterus (Pterosauria, Anurognathidae, Batrachognathinae) and 900 the structure of the pterosaur wing membrane. Proceedings of the Royal Society B: Biological 901 Sciences, 277, 321.

902 Kielan-Jaworowska, Z., Cifelli, R. L., Cifelli, R., and Luo, Z. X. (2004). Mammals from the Age 903 of Dinosaurs: Origins, Evolution, and Structure. Columbia University Press.

904 Lockley, M. G., and Hunt, A. P. (1995). Ceratopsid tracks and associated ichnofauna from the 905 Laramie Formation (Upper Cretaceous: Maastrichtian) of Colorado. Journal of Vertebrate 906 Paleontology, 15, 592-614.

907 Lockley, M. G., Logue, T. J., Moratalla, J. J., Hunt, A. P., Schultz, R. J., and Robinson, J. W. 908 (1995). The fossil trackway Pteraichnus is pterosaurian, not crocodilian: implications for the 909 global distribution of pterosaur tracks. Ichnos, 4, 7-20.

910 Lockley, M. G., and Wright, J. L. (2003). Pterosaur swim tracks and other ichnological evidence 911 of behaviour and ecology. Geological Society, London, Special Publications, 217, 297-313.

912 Lockley, M., Harris, J. D., and Mitchell, L. (2008). A global overview of pterosaur ichnology: 913 tracksite distribution in space and time. Zitteliana, B28, 185-198.

914 Lü, J. C., Unwin, D. M., Jin, X., Liu, Y., and Ji, Q. (2010). Evidence for modular evolution in a 915 long-tailed pterosaur with a pterodactyloid skull. Proceedings of the Royal Society B:

916 Biological Sciences, 277, 383-389.

917 Lü, J. C., Unwin, D. M., Zhao, B., Gao, C., and Shen, C. (2012). A new rhamphorhynchid

918 (Pterosauria: Rhamphorhynchidae) from the Middle/Upper Jurassic of Qinglong, Hebei

919 Province, China. Zootaxa, 3158, 1-19.

920 Lü, J. C., Xu, L., Chang, H., and Zhang, X. (2011). A new darwinopterid pterosaur from the

921 Middle Jurassic of western Liaoning, northeastern China and its ecological implications. Acta 922 Geologica Sinica-English Edition, 85, 507-514. 
923 Lü, J. C. and Fucha X. (2010). A new pterosaur (Pterosauria) from Middle Jurassic Tiaojishan 924 Formation of western Liaoning, China. Global Geology, 13, 113-118

925 Mazin, J. M., Hantzpergue, P., Lafaurie, G., and Vignaud, P. (1995). Des pistes de ptérosaures 926 dans le Tithonien de Crayssac (Quercy, France). Comptes rendus de l'Académie des sciences.

927 Série 2. Sciences de la terre et des planètes, 321, 417-424.

928 Mazin, J. M., Billon-Bruyat, J. P., Hantzpergue, P., and Lafaurie, G. (2003). Ichnological

929 evidence for quadrupedal locomotion in pterodactyloid pterosaurs: trackways from the Late

930 Jurassic of Crayssac (southwestern France).Geological Society, London, Special

931 Publications, 217, 283-296.

932 McCrea, R. T., Buckley, L. G., Farlow, J. O., Lockley, M. G., Currie, P. J., Matthews, N. A., and 933 Pemberton, S. G. (2014). A 'terror of tyrannosaurs': the first trackways of tyrannosaurids and 934 evidence of gregariousness and pathology in Tyrannosauridae. PloS one, 9, e103613.

935 McElroy, E. J., Hickey, K. L., and Reilly, S. M. (2008). The correlated evolution of 936 biomechanics, gait and foraging mode in lizards. Journal of Experimental Biology, 211, 10299371040.

938 McGowen, M. R., Padian, K., de Sosa, M. A. and Harmon, R. W. (2002). Description of 939 Montanazhdarcho minor, an azhdarchid pterosaur from the Two Medicine Formation 940 (Campanian) of Montana. Paleobios, 22, 1-9.

941 Meijaard, E., Kitchener, A. C., and Smeenk, C. (2006). 'New Bornean carnivore' is most likely a 942 little known flying squirrel. Mammal Review, 36, 318-324.

943 Meyers, R. A., and Stakebake, E. F. (2005). Anatomy and histochemistry of spread-wing posture 944 in birds. 3. Immunohistochemistry of flight muscles and the "shoulder lock" in 945 albatrosses. Journal of morphology, 263, 12-29.

946 Nussbaum, R. A. (1982). Heterotopic bones in the hindlimbs of frogs of the families Pipidae, 947 Ranidae and Sooglossidae. Herpetologica, 38, 312-320.

948 Nesbitt, S. J. (2011). The early evolution of archosaurs: relationships and the origin of major 949 clades. Bulletin of the American Museum of Natural History, 352, 1-292.

950 Nowak, R. M. (1994). Walker's bats of the world. JHU Press.

951 Ösi, A. (2011). Feeding-related characters in basal pterosaurs: implications for jaw mechanism, 952 dental function and diet. Lethaia, 44, 136-152. 
953 O'Sullivan, M., and Martill, D. M. (2015). Evidence for the presence of Rhamphorhynchus

954 (Pterosauria: Rhamphorhynchinae) in the Kimmeridge Clay of the UK. Proceedings of the

955 Geologists' Association. In press.

956 O'Sullivan, M., Martill, D. M., and Groocock, D. (2013). A pterosaur humerus and

957 scapulocoracoid from the Jurassic Whitby Mudstone Formation, and the evolution of large

958 body size in early pterosaurs. Proceedings of the Geologists' Association, 124, 973-981.

959 Otero, T., and Hoyos, J. M. (2013). Sesamoid elements in lizards. The Herpetological Journal, $960 \quad 23,105-114$.

961 Owen, R. (1870). Monograph of the Fossil Reptilia of the Liassic Formations: Part 2:

962 Pterosauria. Palaeontographical Society Monograph.

963 Padian, K. (1983a). Osteology and functional morphology of Dimorphodon macronyx

964 (Buckland) (Pterosauria: Rhamphorhynchoidea) based on new material in the Yale Peabody

965 Museum. Postilla, 189, 1-44.

966 Padian, K. (1983b). A functional analysis of flying and walking in pterosaurs. Paleobiology, $967 \quad 218-239$.

968 Padian, K. (1985). The origins and aerodynamics of flight in extinct vertebrates. Palaeontology,

$969 \quad 28,413-433$.

970 Padian, K. (2003). Pterosaur stance and gait and the interpretation of trackways. Ichnos, 10, 115971126

972 Padian, K. (2008a). Were pterosaur ancestors bipedal or quadrupedal?: Morphometric,

973 functional, and phylogenetic considerations. Zitteliana, B28, 21-33.

974 Padian, K. (2008b). The Early Jurassic pterosaur Dorygnathus banthensis (Theodori, 1830).

975 Special Papers in Palaeontology, 80, 1-64.

976 Padian, K. (2008c). The Early Jurassic pterosaur Campylognathoides Strand, 1928. Special

977 papers in Palaeontology, 80, 65-107.

978 Padian, K., Li, C., and Pchelnikova, J. (2010). The trackmaker of Apatopus (Late Triassic, North

979 America): implications for the evolution of archosaur stance and gait. Palaeontology, 53, $980 \quad 175-189$.

981 Padian, K., and Olsen, P. E. (1984). The fossil trackway Pteraichnus: not pterosaurian, but 982 crocodilian. Journal of Paleontology, 58, 178-184. 
983 Padian, K., and Rayner, J. M. (1993). The wings of pterosaurs. American Journal of Science, 984 293, 91-166.

985 Parsons, W. L., and Parsons, K. M. (2009). Further descriptions of the osteology of Deinonychus 986 antirrhopus (Saurischia, Theropoda). Bulletin of the Buffalo Society of Natural Sciences, 38, $987 \quad 43$.

988 Pyare, S., and Longland, W. S. (2002). Interrelationships among northern flying squirrels, 989 truffles, and microhabitat structure in Sierra Nevada old-growth habitat. Canadian Journal 990 of Forest Research, 32, 1016-1024.

991 Prondvai, E., and Hone, D. W. (2008). New models for the wing extension in 992 pterosaurs. Historical Biology, 20(4), 237-254.

993 Riskin, D. K., and Hermanson, J. W. (2005a). Biomechanics: Independent evolution of running 994 in vampire bats. Nature, 434, 292-292.

995 Riskin, D. K., Bertram, J. E., and Hermanson, J. W. (2005b). Testing the hindlimb-strength

996 hypothesis: non-aerial locomotion by Chiroptera is not constrained by the dimensions of the 997 femur or tibia. The Journal of Experimental Biology, 208, 1309-1319.

998 Riskin, D. K., Parsons, S., Schutt, W. A., Carter, G. G., and Hermanson, J. W. (2006). Terrestrial 999 locomotion of the New Zealand short-tailed bat Mystacina tuberculata and the common 1000 vampire bat Desmodus rotundus. Journal of Experimental Biology, 209, 1725-1736.

1001 Russell, A. P., and Bels, V. (2001). Biomechanics and kinematics of limb-based locomotion in 1002 lizards: review, synthesis and prospectus. Comparative Biochemistry and Physiology Part 1003 A: Molecular and Integrative Physiology, 131, 89-112.

1004 Sangster, S. (2003). The anatomy, functional morphology and systematics of Dimorphodon 1005 macronyx (Diapsida, Pterosauria). Unpublished Ph.D. thesis, University of Cambridge, 239 1006 pp.

1007 Samuels, J. X., Meachen, J. A. and Sakai, S. A. (2013), Postcranial morphology and the 1008 locomotor habits of living and extinct carnivorans. Journal of Morphology, 274, 121-146.

1009 Sereno, P. C. (1991). Basal archosaurs: phylogenetic relationships and functional 1010 implications. Journal of Vertebrate Paleontology, 11, 1-53.

1011 Sharov, A. G. (1971) Novyiye lyetayushchiye reptili iz myezozoya Kazakhstana i Kirgizii. [New 1012 flying reptiles from the Mesozoic of Kazakhstan and Kirghizia.] Trudy paleont. Inst. 1013 Moscow 130, 104-113. 
1014 Sollberger, D. E. (1940). Notes on the life history of the small eastern flying squirrel. Journal of 1015 Mammalogy, 21, 282-293.

1016 Stafford, B. J., Thorington Jr, R. W., and Kawamichi, T. (2003). Positional behavior of Japanese 1017 giant flying squirrels (Petaurista leucogenys). Journal of Mammalogy, 84, 263-271.

1018 Stevens, K. A. (2013). The articulation of sauropod necks: methodology and mythology. PloS 1019 one, 8 , e78572.

1020 Stevens, K. A., and Parrish, J. M. (1999). Neck posture and feeding habits of two Jurassic 1021 sauropod dinosaurs. Science, 284, 798-800.

1022 Stokes, W. L. (1957) Pterodactyl tracks from the Morrison Formation. Journal of Paleontology, $1023 \quad 31,952-954$.

1024 Sustaita, D., Pouydebat, E., Manzano, A., Abdala, V., Hertel, F., and Herrel, A. (2013). Getting a 1025 grip on tetrapod grasping: form, function, and evolution. Biological Reviews, 88, 380-405.

1026 Taylor, M. P., Wedel, M. J., and Naish, D. (2009). Head and neck posture in sauropod dinosaurs 1027 inferred from extant animals. Acta Palaeontologica Polonica, 54, 213-220.

1028 Taylor, M. P., and Wedel, M. J. (2013). The effect of intervertebral cartilage on neutral posture 1029 and range of motion in the necks of sauropod dinosaurs. PloS one, 8, e78214.

1030 Unwin, D. M. (1987) Pterosaur locomotion: joggers or waddlers? Nature, 327, 13-14.

1031 Unwin, D. M. (1988). New remains of the pterosaur Dimorphodon (Pterosauria:

1032 Rhamphorhynchoidea) and the terrestrial ability of early pterosaurs. Modern Geology, 13, 57103368.

1034 Unwin, D. M. (1989) A predictive method for the identification of vertebrate ichnites and its 1035 application to pterosaur tracks. In D. D. Gillette and M. D. Lockley (eds) Dinosaur Tracks 1036 and Traces, pp. 259-274. Cambridge University Press.

1037 Unwin, D. M. (1996a). Pterosaur tracks and the terrestrial ability of pterosaurs. Lethaia, 29, 3731038386.

1039 Unwin, D. M. (1996b). The fossil record of Middle Jurassic pterosaurs. In Morales M., (ed) The 1040 Continental Jurassic. Bulletin of the Museum of Northern Arizona, 60, 291-304.

1041 Unwin, D. M. (1999). Pterosaurs: back to the traditional model? Trends in ecology \& evolution, $1042 \quad 14,263-268$. 
1043 Unwin, D. M. (2003). On the phylogeny and evolutionary history of pterosaurs. In: Buffetaut, E., 1044 and Mazin, J-M. (eds) Evolution and Palaeobiology of Pterosaurs. Geological Society,

1045 London, Special Publications, 217, 139-190.

1046 Unwin, D. M. (2005). The Pterosaurs from Deep Time. Pi Press.

1047 Unwin, D. M., and Bakhurina, N. N. (1994). Sordes pilosus and the nature of the pterosaur flight 1048 apparatus. Nature, 371, 62-64.

1049 Upchurch, P., Andres, B., Butler, R. J., and Barrett, P. M. (2014). An analysis of pterosaurian

1050 biogeography: implications for the evolutionary history and fossil record quality of the first 1051 flying vertebrates. Historical Biology, (ahead-of-print), 1-21.

1052 Vickaryous, M. K. and Olson, W. M. 2007. Sesamoids and ossicles in the appendicular skeleton.

1053 In Hall, B. K. (ed) Fins Into Limbs: Evolution, Development, and Transformation Part III

1054 Transformation, Chapter 19. University of Chicago Press, Chicago.

1055 Wang, X., Kellner, A. W., Jiang, S., and Meng, X. (2009). An unusual long-tailed pterosaur with 1056 elongated neck from western Liaoning of China. Anais da Academia Brasileira de 1057 Ciências, 81, 793-812.

1058 Wang, X., Kellner, A. W., Jiang, S., Cheng, X., Meng, X., and Rodrigues, T. (2010). New long1059 tailed pterosaurs (Wukongopteridae) from western Liaoning, China. Anais da Academia 1060 Brasileira de Ciências, 82, 1045-1062.

1061 Wellnhofer, P. (1975). Die Rhamphorhynchoidea (Pterosauria) der Oberjura-Plattenkalke 1062 Süddeutschlands. I. Allgemeine Skelletmorphologie. Paläontographica A, 148, 1-33. 1063 Wellnhofer, P. (1987) Die Flughaut von Pterodactylus (Reptilia, Pterosauria) am Beispiel des 1064 Wiener Examplares von Pterodactylus kochi (Wagner). Annln Nathist. Mus. Wien, 88A, $1065 \quad 149-162$.

1066 Wellnhofer, P. (1988). Terrestrial locomotion in pterosaurs. Historical biology, 1, 3-16.

1067 Wellnhofer, P. (1991). The Illustrated Encyclopedia of Pterosaurs. Salamander Books.

1068 Whyte, M. A., and Romano, M. (2014). First record of the pterosaur footprint Pteraichnus from 1069 the Saltwick Formation (Aalenian) of the Cleveland Basin, Yorkshire, UK. Proceedings of 1070 the Yorkshire Geological Society, 60(1), 19-27.

1071 Wild, R. (1978). Die Flugsaurier (Reptilia, Pterosauria) aus der Oberen Trias von Cene bei 1072 Bergamo, Italien. Boll. Soc. paleont. ital. 17, 176-256. 
1073 Wild, R. (1994). A juvenile specimen of Eudimorphodon ranzii Zambelli (Reptilia, Pterosauria) 1074 from the Upper Triassic (Norian) of Bergamo. Riv. Mus. civ. Sci. nat. "E. Caffi" Bergamo, $1075 \quad 16,91-115$.

1076 Wilkinson, M. T. (2008). Three-dimensional geometry of a pterosaur wing skeleton, and its 1077 implications for aerial and terrestrial locomotion. Zoological Journal of the Linnean Society, $1078 \quad 154,27-69$.

1079 Witton, M. P. (2008). A new approach to determining pterosaur body mass and its implications 1080 for pterosaur flight. Zitteliana, B28, 143-158.

1081 Witton, M. P. (2013). Pterosaurs: Natural History, Evolution, Anatomy. Princeton University 1082 Press.

1083 Witton, M. P., and Habib, M. B. (2010). On the size and flight diversity of giant pterosaurs, the 1084 use of birds as pterosaur analogues and comments on pterosaur flightlessness. PloS one, 5, 1085 e13982.

1086 Witton, M. P., and Naish, D. (2008). A reappraisal of azhdarchid pterosaur functional 1087 morphology and paleoecology. PLoS one, 3, e2271.

1088 Young, C. C. (1964). On a new pterosaurian from Sinkiang, China. Vertebrate Palasiatica, 8, $1089221-225$. 
1091 Figure 1. Select hypotheses for non-pterodactyloid poses made in the last 35 years. A, Padian's

1092 (1983a) bipedal Dimorphodon macronyx; B, redrawn lateral view of the 'Roborhamphus' model

1093 discussed by Unwin (2005); C, quadrupedal Dorygnathus banthensis with sprawling forelimbs,

1094 reversed from Padian (2008b).

1095

1096

1097

1098

1099

1100

1101

1102

1103

1104

1105

1106

1107

1108

1109

1110

1111

1112

1113

1114

1115

1116

1117

1118

1119

1120

Figure 2. Pterosaur and bat uropatagia compared. A, line drawing of hindlimb region of Sordes pilosus specimen PIN 2885/3, showing extensive, toe-supported uropatagium (dark shading) and associated brachiopatagia (light shading); B, skeletal reconstruction of Rhamphorhynchus muensteri showing distribution of membranes in non-pterodactyloid pterosaurs based on fossil remains (see Elgin et al. 2011); C, line drawing of hanging common vampire bat Desmodus rotundus, a terrestrially-competent species with an extensive uropatagium analogous to those of non-pterodactyloid pterosaurs. Note Desmodus has a small uropatagium compared to other, terrestrially-adept bat species. Scale bar of A represents $10 \mathrm{~mm}$, other images not to scale. Abbreviations: Brachio, brachiopatagium; CV, caudal vertebrae; Ep, epiphysis, Fem, femur; Fib, fibula; Pel, pelvis; Pro, propatagium; Ta, tarsals; Tib, tibia; Uro, uropatagium; WP, wing phalanx (numerals denote phalanx number); i-v denote pedal digit numbers. A, modified from Unwin and Bakhurina 1994; B, modified from Witton 2013; C, redrawn from photograph in Nowark 1994.

Figure 3. Non-pterodactyloid glenoid morphology. A-C, line drawings of NHMUK R1034 Dimorphodon macronyx left scapulocoracoid in anterodorsal (A), lateral (B) and ventrolateral (C) aspect; D-G, NHMUK R5672, indeterminate rhamphorhynchine right scapulocoracoid in dorsal (D), ventral (E), lateral (F) and anterior (G) aspects; H, photograph of the NHMUK R1034 glenoid ('symmetric' morph), in posteroventral aspect; I, photograph of NHMUK R5672 ('asymmetric' morph) in posteroventral aspect; J, schematic reconstruction of a nonpterodactyloid torso with a symmetric (i) and asymmetric (ii) glenoid conditions, where green shading approximates articulatory range of the humerus in the vertical plane based on extent of articular surface. Scapulocoracoids in J reconstructed based on specimens illustrated herein and models of pectoral anatomy presented for other early pterosaurs (Wellnhofer 1975; 1991; Bennett 2003). Note this is only approximate for Dimorphodon because its sternum remains unknown. ac, acromion process; ar, articular face of glenoid; cor, coracoid, lt, lower tubercle; sc, 
1121 scapula; sb, supraglenoidal buttress. Scale bars represent $10 \mathrm{~mm}$. J, modified from Wellnhofer 1122 (1991).

1123

1124 Figure 4. Pterosaur humeri in anterior view, showing development of lateral and medial 1125 epicondyles adjacent to the capitula and trochleae (shaded grey) in non-pterodactyloids (A-F) 1126 and pterodactyloids (G-I). A, NHMUK 42016, Dimorphodon macronyx; B, YPM 350 F, Di. 1127 macronyx; C, JPM04-0008, Archaeoistiodactylus linglongtaensis; D, Wellnhofer's (1975) 1128 Rhamphorhynchus muensteri humerus; E, SMNS 51827, Dorygnathus banthensis; F, SMNS

1129 50164, Do. banthensis; G, YPM 1164, Pteranodon sp; H, MOR 691, Montanazhdarcho minor; I,

1130 IVPP V.2777, Dsungaripterus weii. Note the relatively poorly developed epicondyles in D-F,

1131 and how the distal humeri of A-C resemble those of pterodactyloids more than other non-

1132 pterodactyloids. Ca, capitulum; LE, lateral epicondyle; ME, medial epicondyle; Tr, trochlea.

1133 Scale bars represent $10 \mathrm{~mm}$, except for $\mathrm{G}$ and $\mathrm{H}$, which equal $50 \mathrm{~mm}$. B, after Padian (1983a); D,

1134 after Wellnhofer (1975); E, after Padian (2008b); G, modified from Bennett (2001); H, after

1135 McGowen et al. (2002); I, after Young (1964). D, E and H are reversed from their sources to

1136 enhance comparability.

1137

1138 Figure 5. Are non-pterodactyloids ubiquitously equipped with short, slender limbs? Skeletal 1139 reconstructions of taxa such as Preondactylus bufarini (A), Dimorphodon macronyx (B) and

1140 Anurognathus ammoni (C and D, in erect and crouched poses respectively, acknowledging the 1141 poorly known glenoid condition of anurognathids) show they have proportionally long, robust

1142 limbs. Only some non-pterodactyloids, including the Early Jurassic campylognathoidid

1143 Campylognathoides liasicus (E) and Late Jurassic rhamphorhynchine Rhamphorhynchus

1144 muensteri (F) have proportionally short and slender hindlimbs. Preondactylus has been

1145 reconstructed with erect forelimbs based on its grossly similar humeral morphology to

1146 Dimorphodon, although it remains to be established that this similarity extends to more detailed

1147 forelimb anatomy. Scale bars represent $100 \mathrm{~mm}$, except for C and D, which represent $50 \mathrm{~mm}$.

1148 Skeletal reconstructions modified from Witton (2013).

1149

1150 Figure 6. Antungual sesamoids in pterosaurs. A, manus and pes of NHMUK 41212

1151 Dimorphodon macronyx; B, partial pes skeleton of GSM 1546 Di. macronyx; C, manus of BSP 
11521938 I 49 Dorygnathus banthensis; D, proposed interactions of pterosaur unguals with hard 1153 substrates, and utilisation of antungual sesamoids (extensor tendon shown in grey shading). Di,

1154 terminal phalanges of Dimorphodon manual digit 2 show as resting on a hard substrate without

1155 loading; Dii, passive hyperextension of the ungual, where pulling or depressing the phalanges

1156 (force vectors shown with arrows) retract the ungual to contact the sesamoid; Diii, active

1157 hyperextension of the ungual, where the extensor tendon is pulled to clear the ungual tip of the

1158 ground using the additional lever arm length afforded by the sesamoid. A-C, shading and

1159 numbers denote identification of clawed digits (Arabic numerals for manual digits, unary for

1160 pedal). Some skeletal elements present on the illustrated specimens are omitted for clarity. mc1-

1161 3, metacarpals 1-3; mt1-4, metatarsals 1-4; mt5, metatarsal 5; pd v, pedal digit 5; r, dorsal rib; s,

1162 sesamoids; wmc, wing metacarpal; wp, wing finger proximal phalanx. Scale bars represent 10

$1163 \mathrm{~mm}$.

1164 Figure 7. Complex distribution of characteristics linked to terrestrial capabilities in non-

1165 pterodactyloids in a simplified pterosaur phylogeny (based on Lü et al. 2012). Other pterosaur

1166 phylogenies suggest different arrangements of non-pterodactyloid taxa (see text for details), but

1167 the distribution of these characteristics would be as complex, if not more so, in competing

1168 arrangements.

1169

1170 Figure 8. Potential variation in terrestrial locomotion gait in non-pterodactyloid pterosaurs. A,

1171 life restoration of the Early Jurassic rhamphorhynchine Dorygnathus banthensis with obligated

1172 crouching, somewhat sprawled forelimbs; B, life restoration of the Early Jurassic Dimorphodon

1173 macronyx with fully adducted humeri and completely erect gait, shown here facilitating

1174 subcursorial, rapid terrestrial locomotion in pursuit of sphenodontian prey. Both animals are

1175 restored with retracted claws on digits possessing antungual sesamoids. 


\section{1}

Select hypotheses for non-pterodactyloid poses made in the last 35 years

Figure 1. Select hypotheses for non-pterodactyloid poses made in the last 35 years . A, Padian's (1983a) bipedal Dimorphodon macronyx; B, redrawn lateral view of the 'Roborhamphus' model discussed by Unwin (2005); C, quadrupedal Dorygnathus banthensis with sprawling forelimbs, reversed from Padian (2008b).

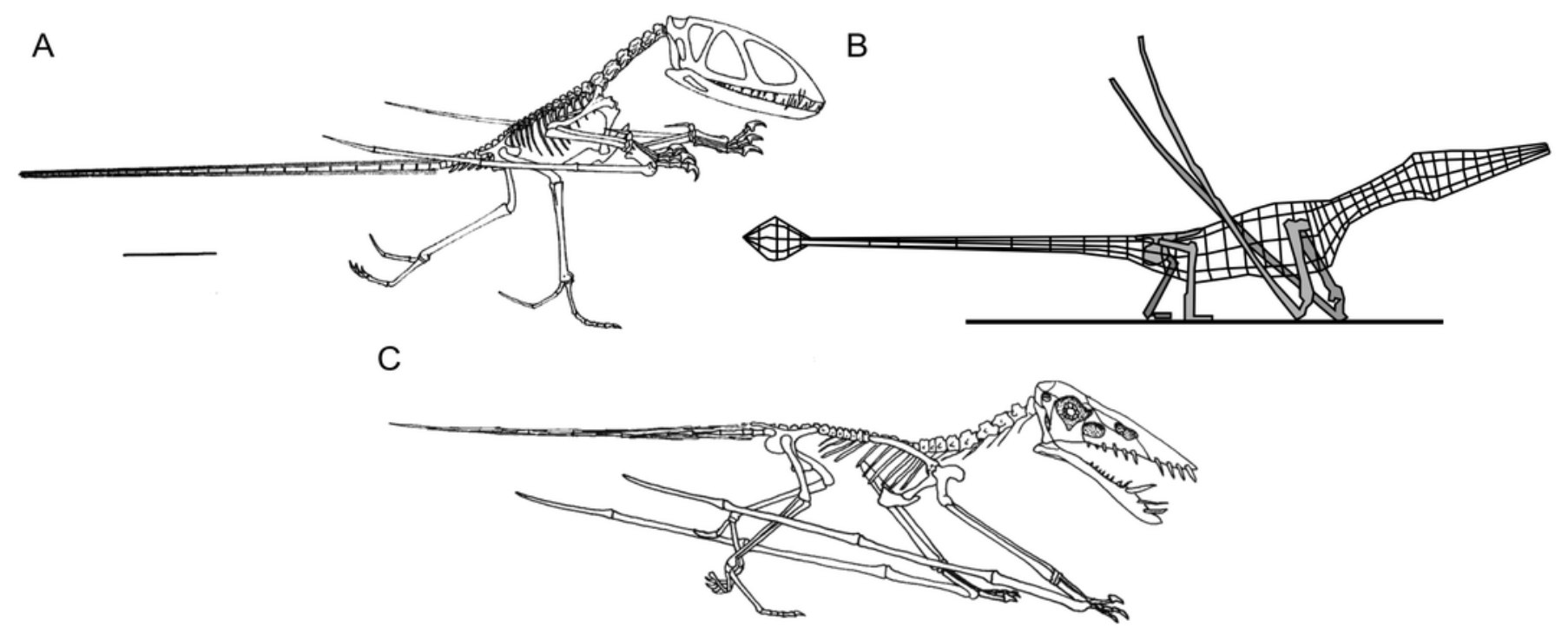




\section{2}

Pterosaur and bat uropatagia compared

Figure. 2. Pterosaur and bat uropatagia compared. A, line drawing of hindlimb region of Sordes pilosus specimen PIN 2885/3, showing extensive, toe-supported uropatagium (dark shading) and associated brachiopatagia (light shading); B, skeletal reconstruction of Rhamphorhynchus muensteri showing distribution of membranes in non-pterodactyloid pterosaurs based on fossil remains (see Elgin and Hone 2011); C, line drawing of hanging common vampire bat Desmodus rotundus, a terrestrially-competent species with an extensive uropatagium analogous to those of non-pterodactyloid pterosaurs. Note Desmodus has a small uropatagium compared to other, terrestrially-adept bat species. Scale bar of A represents $10 \mathrm{~mm}$, other images not to scale. Abbreviations: Brachio, brachiopatagium; CV, caudal vertebrae; Ep, epiphysis, Fem, femur; Fib, fibula; Pel, pelvis; Pro, propatagium; Ta, tarsals; Tib, tibia; Uro, uropatagium; WP, wing phalanx (numerals denote phalanx number); i$\checkmark$ denote pedal digit numbers. A, modified from Unwin and Bakhurina 1994; B, modified from Witton 2013; C, redrawn from photograph in Nowark 1994. 


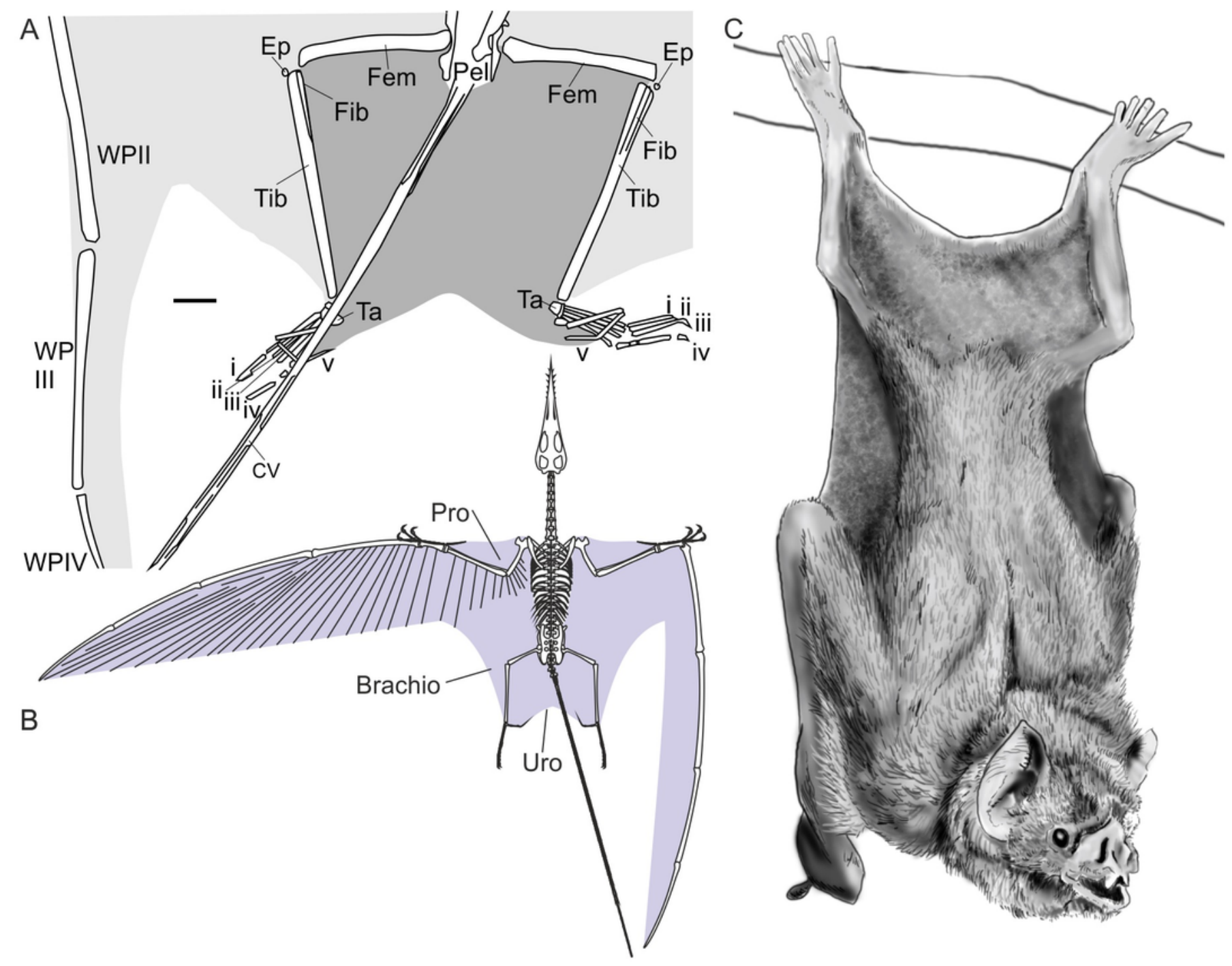




\section{3}

Non-pterodactyloid glenoid morphology

Figure 3. Non-pterodactyloid glenoid morphology. A-C, line drawings of NHMUK R1034 Dimorphodon macronyx left scapulocoracoid in anterodorsal (A), lateral (B) and ventrolateral (C) aspect; D-G, NHMUK R5672, indeterminate rhamphorhynchine right scapulocoracoid in dorsal (D), ventral (E), lateral (F) and anterior (G) aspects; $H$, photograph of the NHMUK R1034 glenoid ('symmetric' morph), in posteroventral aspect; I, photograph of NHMUK R5672 ('asymmetric' morph) in posteroventral aspect; J, schematic reconstruction of a nonpterodactyloid torso with a symmetric (i) and asymmetric (ii) glenoid conditions, where green shading approximates articulatory range of the humerus in the vertical plane based on extent of articular surface. Scapulocoracoids in J reconstructed based on specimens illustrated herein and models of pectoral anatomy presented for other early pterosaurs (Wellnhofer 1975; 1991; Bennett 2003). Note this is only approximate for Dimorphodon because its sternum remains unknown. ac, acromion process; ar, articular face of glenoid; cor, coracoid, It, lower tubercle; sc, scapula; sb, supraglenoidal buttress. Scale bars represent $10 \mathrm{~mm}$. J, modified from Wellnhofer (1991). 


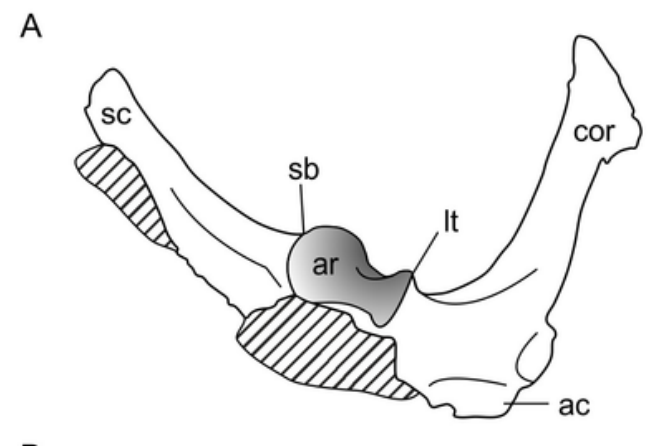

D
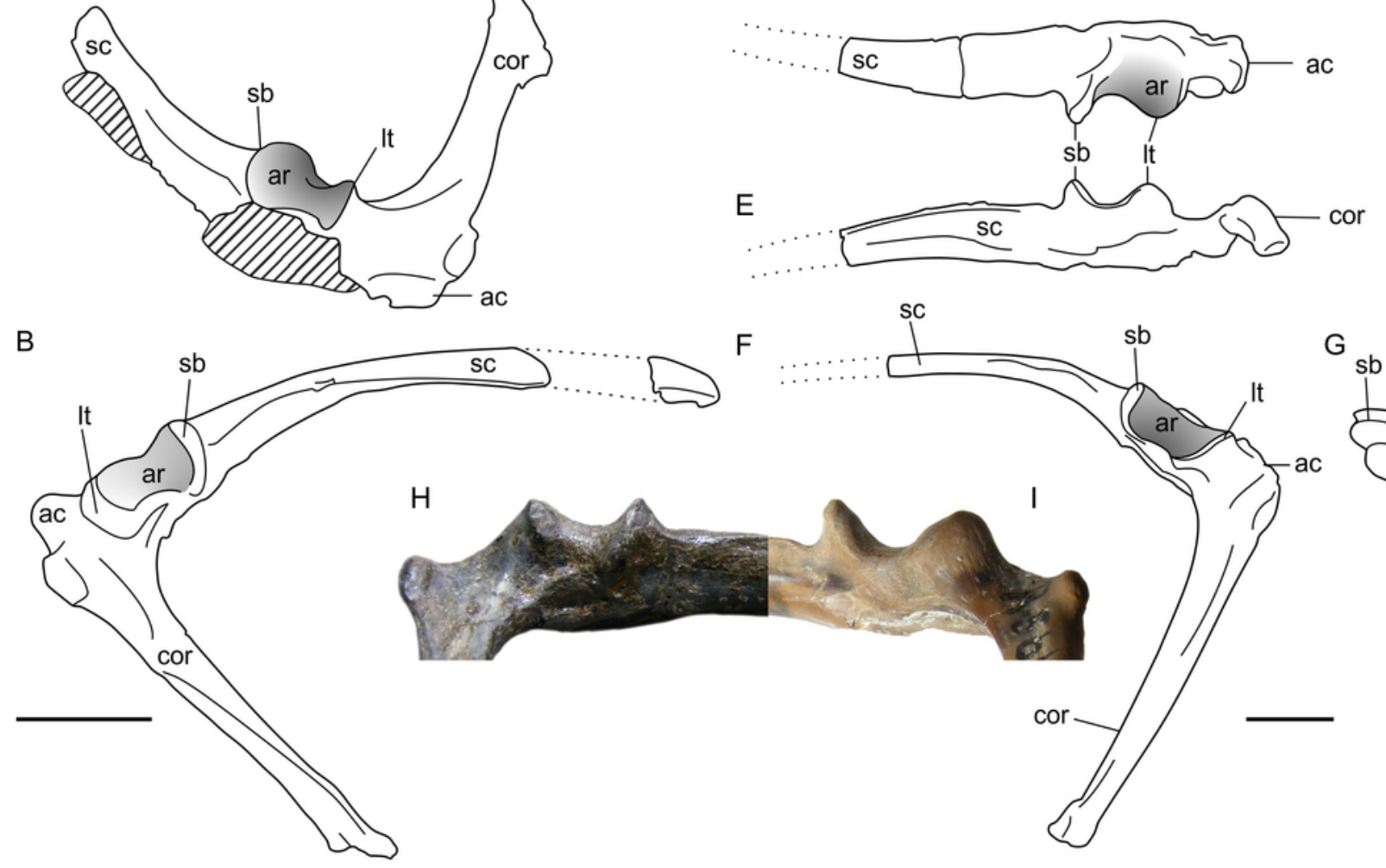

C
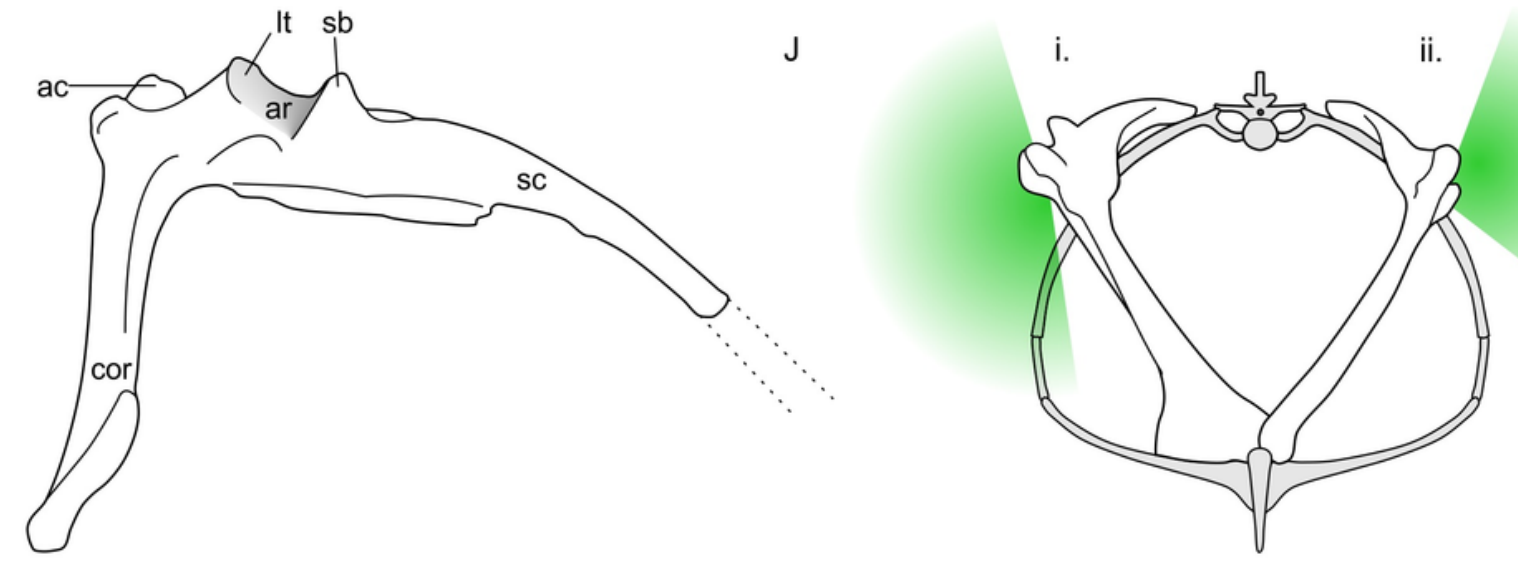


\section{4}

Pterosaur humeri in anterior view

Figure 4. Pterosaur humeri in anterior view, showing development of lateral and medial epicondyles adjacent to the capitula and trochleae (shaded grey) in non-pterodactyloids (A-F) and pterodactyloids (G-I). A, NHMUK 42016, Dimorphodon macronyx; B, YPM 350 F, Di. macronyx ; C, JPM04-0008, Archaeoistiodactylus linglongtaensis; D, Wellnhofer's (1975) Rhamphorhynchus muensteri humerus; E, SMNS 51827, Dorygnathus banthensis; F, SMNS 50164, Do. banthensis; G, YPM 1164, Pteranodon sp; H, MOR 691, Montanazhdarcho minor; I, IVPP V.2777, Dsungaripterus weii. Note the relatively poorly developed epicondyles in D-F, and how the distal humeri of A-C resemble those of pterodactyloids more than other nonpterodactyloids. Ca, capitulum; LE, lateral epicondyle; ME, medial epicondyle; Tr, trochlea.

Scale bars represent $10 \mathrm{~mm}$, except for $\mathrm{G}$ and $\mathrm{H}$, which equal $50 \mathrm{~mm}$. B, after Padian (1983a); D, after Wellnhofer (1975); E, after Padian (2008b); G, modified from Bennett (2001); H, after McGowen et al. (2002); I, after Young (1964). D, E and H are reversed from their sources to enhance comparability. 2 I? ? $0<\sim \mathrm{Tm}$

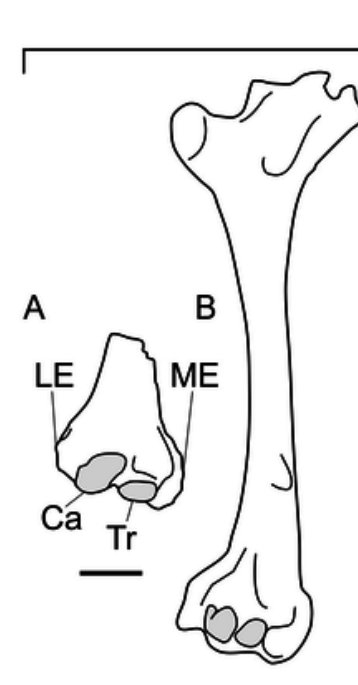

Non-pterodactyloids

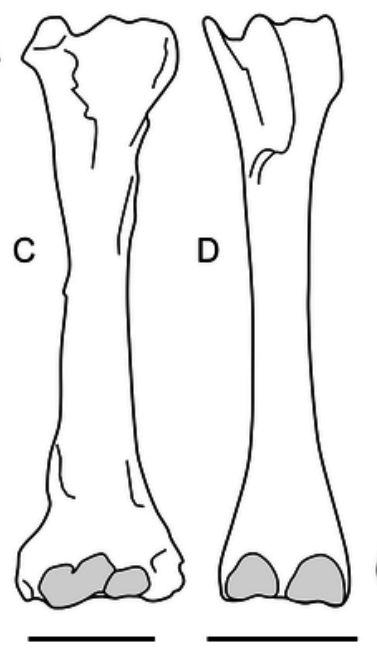

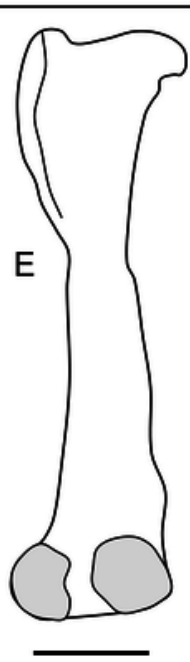

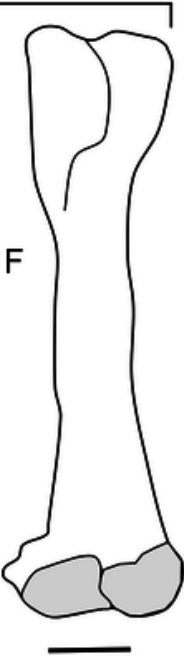

Pterodactyloids

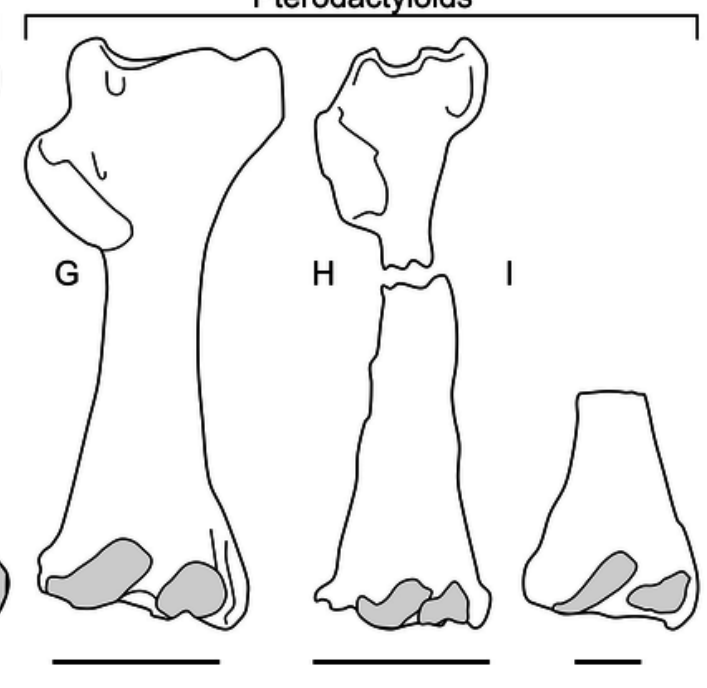




\section{5}

Skeletal reconstructions of non-pterodactyloid pterosaurs

Figure 5. Are non-pterodactyloids ubiquitously equipped with short, slender limbs? Skeletal reconstructions of taxa such as Preondactylus bufarini (A), Dimorphodon macronyx (B) and Anurognathus ammoni ( $C$ and $\mathrm{D}$, in erect and crouched poses respectively, acknowledging the poorly known glenoid condition of anurognathids) show they have proportionally long, robust limbs. Only some non-pterodactyloids, including the Early Jurassic campylognathoidid Campylognathoides liasicus (E) and Late Jurassic rhamphorhynchine Rhamphorhynchus muensteri (F) have proportionally short and slender hindlimbs. Preondactylus has been reconstructed with erect forelimbs based on its grossly similar humeral morphology to Dimorphodon, although it remains to be established that this similarity extends to more detailed forelimb anatomy. Scale bars represent $100 \mathrm{~mm}$, except for $C$ and $D$, which represent $50 \mathrm{~mm}$. Skeletal reconstructions modified from Witton (2013). <!--? $0[\mathrm{~b}]$ 


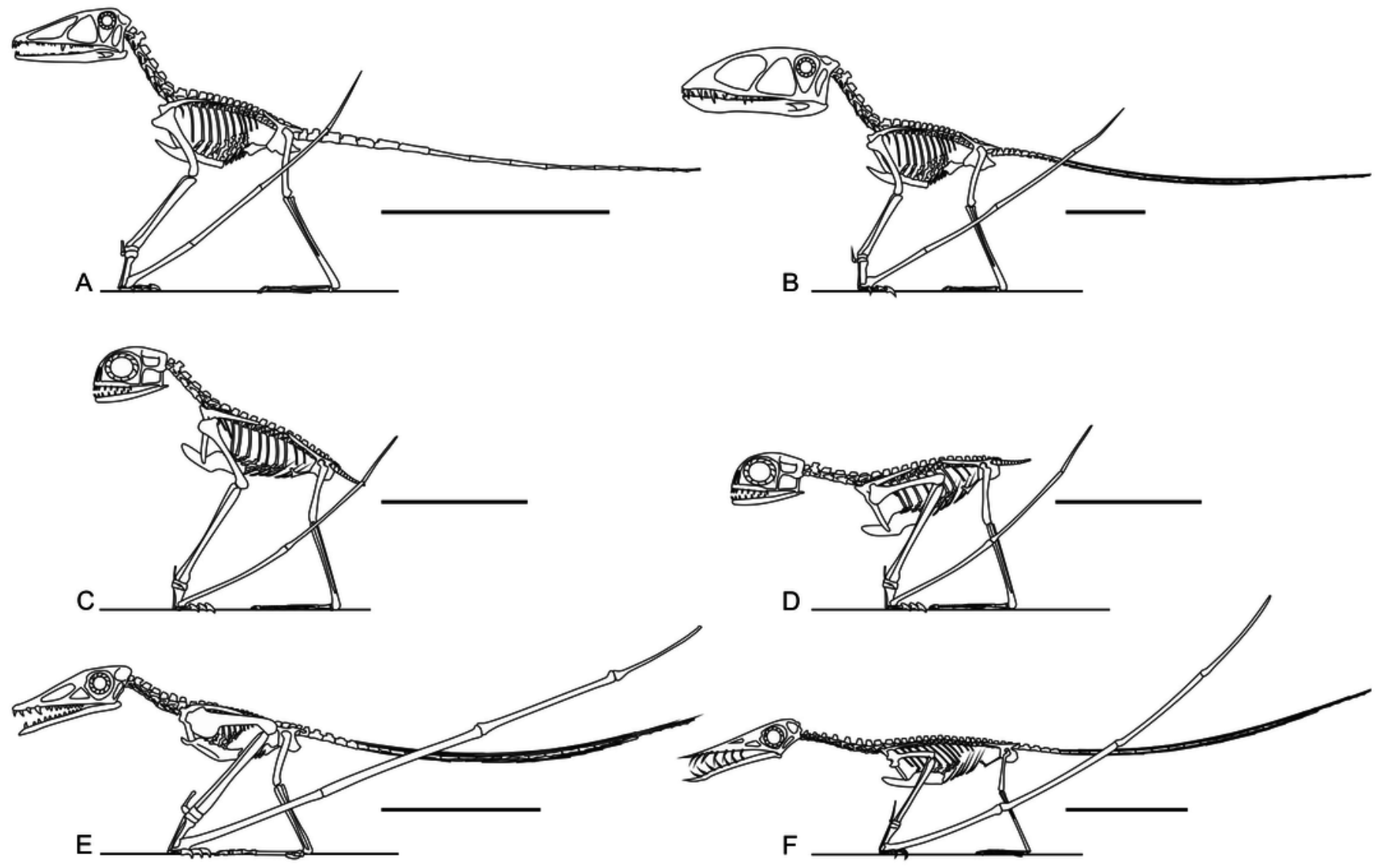




\section{6}

Antungual sesamoids in pterosaurs

Figure 6. Antungual sesamoids in pterosaurs. A, manus and pes of NHMUK 41212

Dimorphodon macronyx; B, partial pes skeleton of GSM 1546 Di. macronyx; C, manus of BSP 1938 I 49 Dorygnathus banthensis; D, proposed interactions of pterosaur unguals with hard substrates, and utilisation of antungual sesamoids (extensor tendon shown in grey shading). $\mathrm{Di}$, terminal phalanges of Dimorphodon manual digit 2 show as resting on a hard substrate without loading; Dii, passive hyperextension of the ungual, where pulling or depressing the phalanges (force vectors shown with arrows) retract the ungual to contact the sesamoid; Diii, active hyperextension of the ungual, where the extensor tendon is pulled to clear the ungual tip of the ground using the additional lever arm length afforded by the sesamoid. A-C, shading and numbers denote identification of clawed digits (Arabic numerals for manual digits, unary for pedal). Some skeletal elements present on the illustrated specimens are omitted for clarity. mc1-3, metacarpals 1-3; mt1-4, metatarsals 1-4; mt5, metatarsal 5; pd v, pedal digit 5; r, dorsal rib; s, sesamoids; wmc, wing metacarpal; wp, wing finger proximal phalanx. Scale bars represent $10 \mathrm{~mm}$.

A

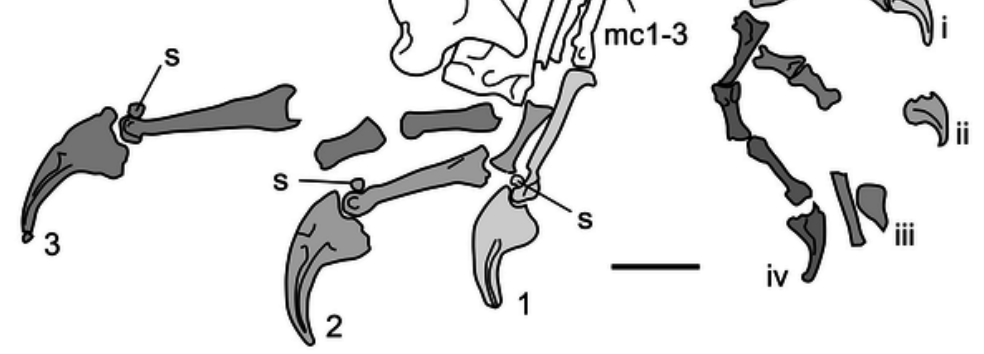

B

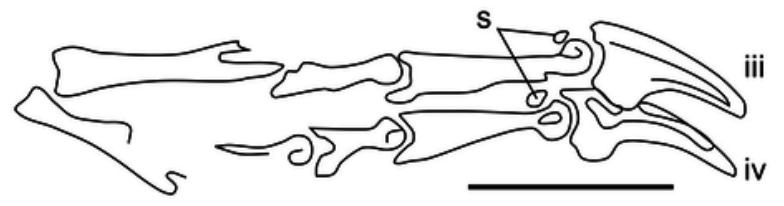

C

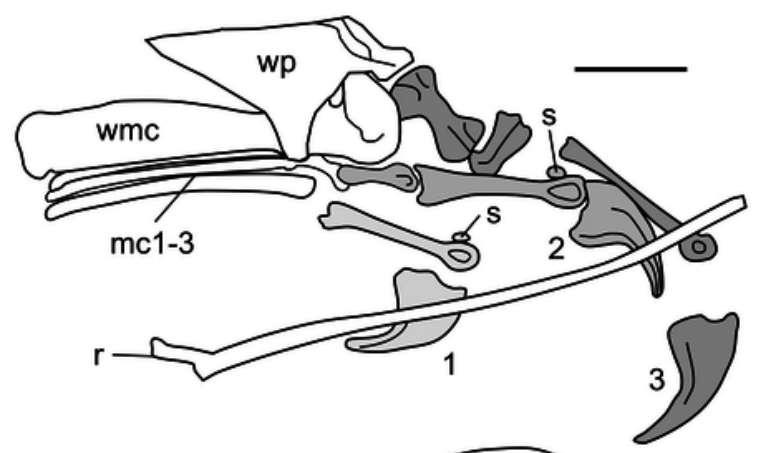

Di

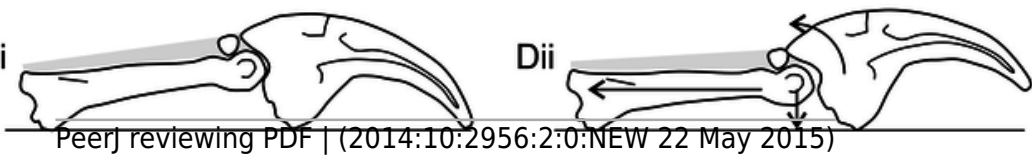

Diii

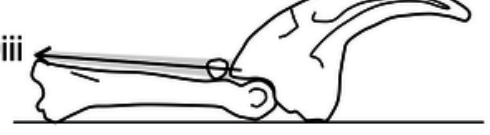




\section{7}

Distribution of characteristics linked to terrestrial capabilities in non-pterodactyloids in a simplified pterosaur phylogeny

Figure 7. Complex distribution of characteristics linked to terrestrial capabilities in nonpterodactyloids in a simplified pterosaur phylogeny (based on Lü et al. 2012). Other pterosaur phylogenies suggest different arrangements of non-pterodactyloid taxa (see text for details), but the distribution of these characteristics would be as complex, if not more so, in competing arrangements.

All limbs long and robust Asymmetric glenoid

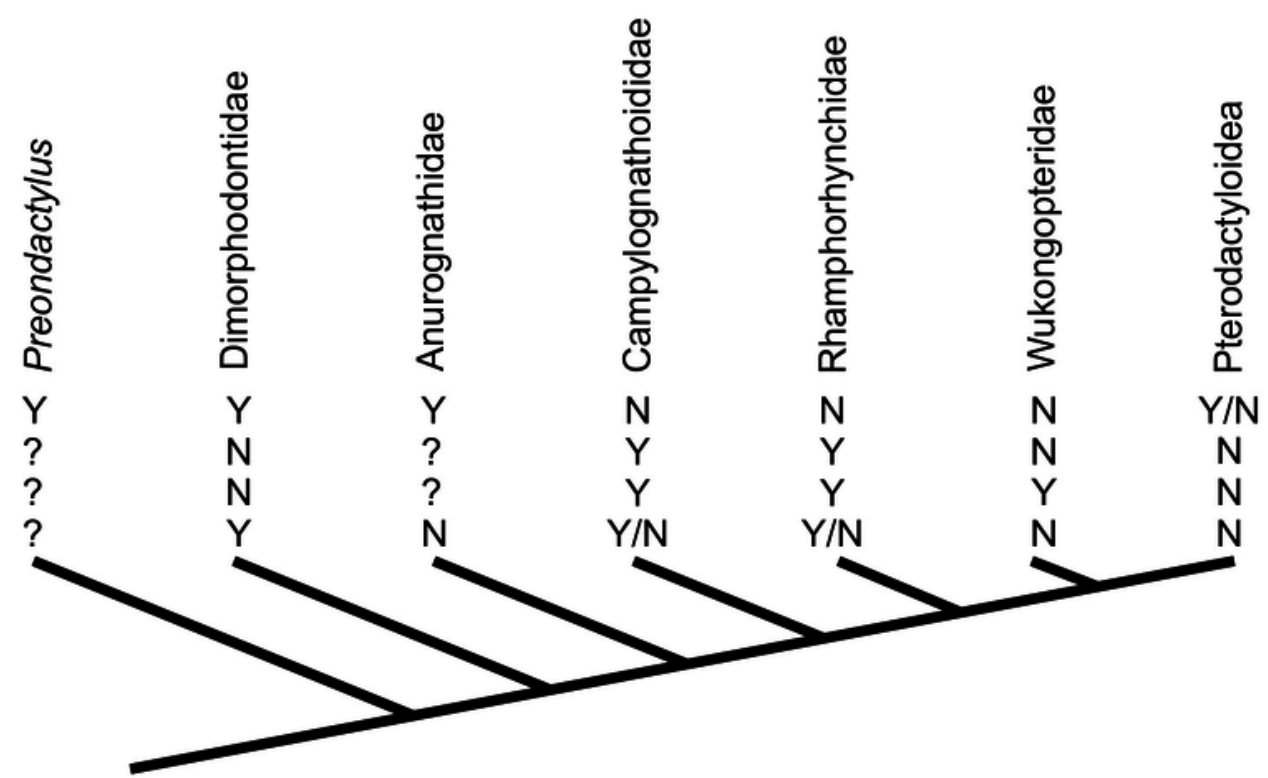


8

Potential variation in terrestrial locomotion gait in non-pterodactyloid pterosaurs

Figure 8. Potential variation in terrestrial locomotion gait in non-pterodactyloid pterosaurs. A, life restoration of the Early Jurassic rhamphorhynchine Dorygnathus banthensis with obligated crouching, somewhat sprawled forelimbs; B, life restoration of the Early Jurassic Dimorphodon macronyx with fully adducted humeri and completely erect gait, shown here facilitating subcursorial, rapid terrestrial locomotion in pursuit of sphenodontian prey. Both animals are restored with retracted claws on digits possessing antungual sesamoids. $\mathrm{ml}>0$ 
PeerJ Reviewing Manuscript

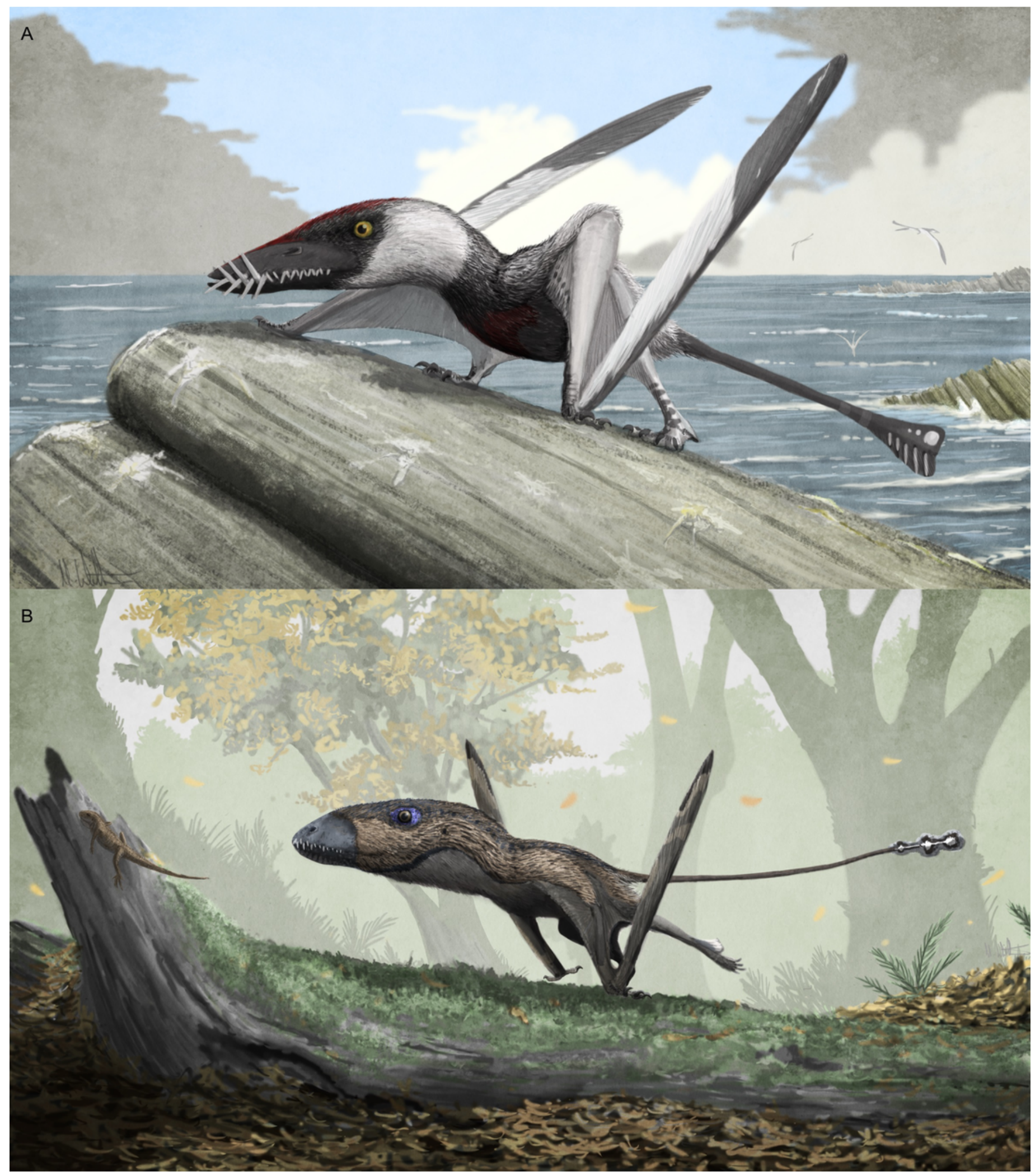

